\title{
Impact of an external boundary wall on indoor flow field and natural cross-ventilation in an isolated family house using numerical simulations
}

\author{
Sherzad Hawendi*, Shian Gao \\ Department of Engineering, University of Leicester, LE1 7RH, United Kingdom \\ * Corresponding author: phone: +44(0)116 252 2874; fax: +44(0)116 252 2525; e-mail: sh567@ le.ac.uk.
}

\section{ABSTRACT}

The external boundary wall is a main architectural feature of a typical residential building in Iraq, which is expected to decrease the rate of airflow entering the openings of the building. In this study, the impact of an external boundary wall on natural cross-ventilation and flow patterns inside an isolated family house was analyzed using computational fluid dynamics (CFD) simulations. The wall was located in front of the building and three different conditions were tested: basic case (without a wall) and two cases using walls of different heights. The study employed the techniques of large eddy simulation (LES) with the dynamic Smagorinsky subgrid-scale model because of the unsteady flow and high turbulence around the building. The CFD simulations were validated against the available wind tunnel experiments. It was observed that the external boundary wall created well distributed indoor air flow and improved the indoor environment regarding the mean velocity inside the building. Also, increasing the height of the wall by $20 \%$ did not offer noticeable improvement on the mean velocity distribution, whereas the ventilation airflow rate was reduced significantly to less than half when the wall was present. The results of this study are expected to inform building designers of the impact of an external boundary wall on the flow patterns in relation to the rate of ventilation and indoor mean velocity.

Keywords: Natural ventilation, CFD, Boundary wall, Wind comfort 


\section{NOMENCLATURE}

\begin{tabular}{|c|c|}
\hline A & Area $\left(\mathrm{m}^{2}\right)$ \\
\hline $\mathrm{C}$ & Dynamic Smagorinsky coefficient \\
\hline $\mathrm{H}$ & Height of the building(m) \\
\hline $\mathrm{I}_{\mathrm{u}}$ & Turbulence intensity \\
\hline$k_{\text {res }}$ & Resolved turbulent kinetic energy $\left(\mathrm{m}^{2} / \mathrm{s}^{2}\right)$ \\
\hline$k_{\text {num }}$ & Numerical dissipation turbulent kinetic energy $\left(\mathrm{m}^{2} / \mathrm{s}^{2}\right)$ \\
\hline $\mathrm{k}_{\mathrm{sgs}}$ & Subgrid scale turbulent kinetic energy $\left(\mathrm{m}^{2} / \mathrm{s}^{2}\right)$ \\
\hline $\mathrm{k}_{\mathrm{t}}$ & Total turbulent kinetic energy $\left(\mathrm{m}^{2} / \mathrm{s}^{2}\right)$ \\
\hline $\operatorname{Re}$ & Average Reynolds number based on the building heig \\
\hline $\mathrm{Q}^{*}$ & Dimensionless ventilation rate \\
\hline $\mathrm{u}_{\tau}$ & Friction velocity(m/s) \\
\hline $\mathrm{U}(\mathrm{y})$ & Mean velocity at height $y$ above the ground(m/s) \\
\hline $\mathrm{U}_{\text {ref }}$ & External wind speed at the building height(m/s) \\
\hline $\mathrm{y}^{+}$ & Dimensionless wall (normal) distance, $\mathrm{u}_{\tau} \mathrm{y} / v$ \\
\hline $\mathrm{y}_{0}$ & Aerodynamics roughness length(m) \\
\hline \multicolumn{2}{|c|}{ Greek symbols } \\
\hline$\varepsilon$ & Rate of dissipation of turbulent kinetic energy $\left(\mathrm{m}^{2} / \mathrm{s}^{3}\right)$ \\
\hline $\mathrm{k}$ & Von Karman constant \\
\hline$\mu$ & Dynamic viscosity(kg/m.s) \\
\hline$\mu_{\mathrm{t}}$ & Turbulent viscosity (Pa.s) \\
\hline$v$ & Kinematic viscosity $\left(\mathrm{m}^{2} / \mathrm{s}\right)$ \\
\hline$\rho$ & Density $\left(\mathrm{kg} / \mathrm{m}^{3}\right)$ \\
\hline $\bar{S}_{\mathrm{ij}}$ & Rate of strain tensor \\
\hline$\tau_{\mathrm{ij}}$ & Subgrid-scale stress \\
\hline$\Delta_{\mathrm{S}}$ & Volume of the computational cell \\
\hline
\end{tabular}

\section{Introduction}

Natural ventilation is considered beneficial for obtaining thermal comfort in a hot summer and helping to meet a building's cooling loads without using mechanical air conditioning systems. Successful ventilation is determined as having high thermal comfort and adequate fresh air for the ventilated spaces and having small or no energy use for active heating, ventilation and air conditioning (HVAC) [1, 2]. Office buildings in the United Kingdom have saved cooling loads of 14 to $41 \mathrm{kWh} / \mathrm{m}^{2}$ by using natural ventilation, which represent a $10 \%$ annual energy saving [3]. 
Feng et al. [4] showed that the potential energy saving in office buildings was around $30 \%$. The factors which have the most effects on the performance of natural ventilation in buildings are the outside weather, which is changeable, building configurations, external landscape and neighborhood effect $[5,6]$. These factors increase the difficulty of maintaining steady conditions inside the building. External landscaping and artificial elements form an integral part of a building's environment and may have a positive or negative impact on the ventilation rate and flow patterns of the building, therefore, decisions regarding the placement and selection of external factors are crucial for a designer [6]. Assessing a natural ventilation system based on the saving energy only is not sufficient and there are four environmental factors (air velocity, air temperature, radiant temperature and relative humidity) and two personal factors (clothing insulation and metabolic heat) must be considered [7]. Providing the appropriate indoor air speed is a part of human comfort, therefore, ASHRAE standard 55-2013 recommends the maximum air velocity to be $0.2 \mathrm{~m} / \mathrm{s}[8]$.

Many researchers have utilized the aerodynamic potential of building façades to investigate their enhancement effect on indoor and outdoor airflow exchanges for both single-sided and cross ventilation buildings. Typical building façades include a wind catchers [9-13] venturi-shaped roof $[14,15]$, wing walls [16], a ventilation shaft [17], a balcony [18-21] and eaves [22-25], while other researchers focused on the influences of external factors on ventilation rates and indoor air patterns such as sheltering building [26-30] and external landscape [6, 31].

Fred et al. [27] used both computational and experimental methods to investigate the performance of natural ventilation in long rows of buildings. Their study concluded that the best options for flow inlets and outlets depend on the building spacing and wind direction. The solid wall windbreak was tested by Ikeguchi et al. [32] who examined the ability of windbreaks to 
control air contaminants from livestock buildings. The air pollutant which accumulates behind the solid wall can be emitted from the building by spraying with water. Aynsley [33] concluded that vegetation can improve external wind direction and increase the rate of ventilation. The effects of some environmental factors on air flow in and around buildings were examined by Lam et al. [28]. They concluded that any change in these factors can significantly affect the boundary conditions and consequently the indoor airflow parameters such as pressure, velocity magnitude and distribution pattern. Tuan et al. [29] investigated the impact of the sheltered building on the natural ventilation and flow pattern of a downstream building in tropical regions. It was found that the possibility of ventilation was increased by increasing the sheltered distance. Some studies mentioned that obstacles around buildings, such as trees, block wind flow, reduce wind velocity and increase average pollutant concentrations [34-35]. Ai et al. [18] studied the effect of balconies on the indoor ventilation performance of low-rise building by examining mass flow rate and average velocity on the working plane, the numerical results indicated that, for single-sided ventilation, the provision of balconies increased mass flow rate and reduced average velocity on the working plane in most rooms, while for cross ventilation, this provision had no significant effect under normally or obliquely incident wind conditions. Mohamed et al. [21] suggested that balconies could improve the level of thermal comfort and indoor air quality of apartments for highrise building by providing greater indoor air speed and better ventilation performance, respectively. Amos et al. [6] tested the impact of two different boundary walls, solid and perforated, on indoor airflow and patterns inside a typical residential building in Ghana with steady RANS simulations. The CFD results showed that the indoor airflow was significantly affected by the distance and height of the boundary wall and could be reduced to $40 \%$. The effect of the surrounding buildings on the cross-ventilated flow was also investigated by Tong et al [30], and 
they concluded that the air flow rate was reduced to approximately $30 \%$ for the sheltered building due to the presence of the surrounding buildings.

The external boundary wall is a commonly used feature in low-rise buildings in Iraq and some other countries. A typical envelope design for residential buildings in Iraq is limited between 1$1.5 \mathrm{~m}$ in height with a thickness of $0.2 \mathrm{~m}$. Higher wall than this limit will affect on the features of the building and reduce the ventilation rate considerably while lower wall than this limit is undesirable. Generally, there is limited knowledge and understanding of the impact of external boundary walls on indoor air patterns and flow rates. In addition, not enough studies have focused on their influence on unsteady cross-ventilation, where the flow with the presence of a wall is of high turbulence with more unsteadiness. Furthermore, a description of the ventilation rate using a constant value is incomplete if the fluctuation intensity is too large [36]. Therefore, this paper focuses on investigating the impact of an external boundary wall on improving indoor mean velocity, flow pattern inside rooms and natural cross-ventilation in an isolated residential house in Iraq using the LES method with a dynamic sub-grid scale model. In addition, the study examines the effects of two wall heights at $1 \mathrm{~m}$ and $1.2 \mathrm{~m}$. The findings from this study are expected to improve the understanding about the effect of external wall on natural ventilation and indoor air environment in residential buildings.

\section{Numerical Method}

In this study, the LES method was used to simulate the cross ventilation in the residential building with an external wall, because LES is much better in predicting and capturing the turbulent feature of the flow than RANS modelling in the wake region behind the external wall [37-39]. By filtering the time-dependent Navier-Stokes equations, the governing equations used 
for large eddies of an incompressible flow of a Newtonian fluid can be obtained [40]:

$$
\begin{gathered}
\frac{\partial \rho}{\partial t}+\frac{\partial\left(\rho \bar{u}_{i}\right)}{\partial x_{i}}=0 \\
\frac{\partial \bar{\rho}_{i}}{\partial t}+\frac{\partial\left(\rho \bar{u}_{i} \bar{u}_{j}\right)}{\partial x_{j}}=-\frac{\partial \bar{p}}{\partial x_{i}}+\frac{\partial}{\partial x_{j}}\left\{\mu\left(\frac{\partial \bar{u}_{i}}{\partial x_{j}}+\frac{\partial \bar{u}_{j}}{\partial x_{i}}\right)\right\}-\frac{\partial \tau_{i j}}{\partial x_{j}}
\end{gathered}
$$

where the subscripts $\mathrm{i}, \mathrm{j}=1,2,3$ represent the $\mathrm{x}, \mathrm{y}$ and $\mathrm{z}$ directions, respectively; $\mathrm{t}$ represents the time; $\mathrm{u}$ and $\mathrm{P}$ are the velocity and pressure, the over-bar represents these quantities as spatially averaged values [5], and $\tau_{\mathrm{ij}}$ is the sub-grid scale stress term and represents the impact of nonresolved small-scale eddies on large-scale eddies. Because $\tau_{\mathrm{ij}}$ in the LES method is unknown, modelling is needed to close the governing equations. The Boussinesq hypothesis is used to compute $\tau_{\mathrm{ij}}$ using the expression below [40]:

$$
\tau_{i j}=\left(\frac{1}{3}\right) \tau_{k k} \delta_{i j}-2 \mu_{t} \bar{S}_{i j}
$$

where $\mu_{t}$ is the viscosity of the sub-grid scale turbulence, defined as

$$
\mu_{t}=\rho\left(C \Delta_{s}\right)^{2} \sqrt{2 \bar{S}_{i j} \bar{S}_{i j}}
$$

where $C$ is the dynamic Smagorinsky coefficient and varies with time and space, which allows the Smagorinsky model to overcome transitional flows and to include near-wall damping effects in a natural manner [41]. This model was implemented by some researchers in the field of computational wind engineering [42-44]. In this method, $C$ is calculated as

$$
C=\frac{L_{i j} M_{i j}}{2 M_{i j} M_{i j}}
$$

where $L_{i j}$ is the Leonard stress tenser defined as [40]:

$$
L_{i j}=\widetilde{\bar{u}_{\imath} \bar{u}_{\jmath}}-\widetilde{\bar{u}_{\imath}} \widetilde{\bar{u}_{J}}
$$

and

$$
M_{i j}=\left|\overline{\bar{S} \mid \bar{S}_{l \jmath}}-\tilde{\bar{\Delta}}^{2}\right| \tilde{\bar{S}} \mid \tilde{\bar{S}}_{i j}
$$




\section{Cases description}

The basic configuration of the studied model was an isolated house without a boundary wall, including partitions from inside; this layout is simple and represents an average house for an average family in Iraq. The height of the building was $(\mathrm{H})$ and had base dimensions of $(3.33 \times 2.66) \mathrm{H}$. The ratio of openings to façade of the building was 0.03 . There were two square openings $(0.2 \mathrm{H})$ on the front wall and two openings at the rear of the building. The building consisted of five rooms: kitchen (A), sitting room (B), living room (C), and two bedrooms (D \& E) as shown in Fig. 1. The front view of the reduced-scale building model with the sizes and dimensions of the openings are presented in Fig. 2. Three cases were used in this study and the details are provided in Table 1 . The first case was the basic case, while the second and third cases were based on the same basic model, but with the addition of an external boundary wall with height $0.333 \mathrm{H}$ and $0.40 \mathrm{H}$ respectively. In all cases, the Reynolds number is equal to $13.9 \times 10^{3}$, based on the height of the building, which represents turbulent flow [45]. The wind speed at the height of the building $\left(\mathrm{U}_{\mathrm{ref}}\right)$ was $7 \mathrm{~m} / \mathrm{s}$ with an angle of incidence of $0^{\circ}$.

\section{Table 1}

Cases description

\begin{tabular}{ll} 
Cases study & Case description \\
\hline Case- I & Basic case (without boundary wall) \\
Case-EF & Basic case +boundary wall with height $0.333 \mathrm{H}$ \\
Case-EFH & Basic case +boundary wall with height $0.40 \mathrm{H}$ \\
\hline
\end{tabular}




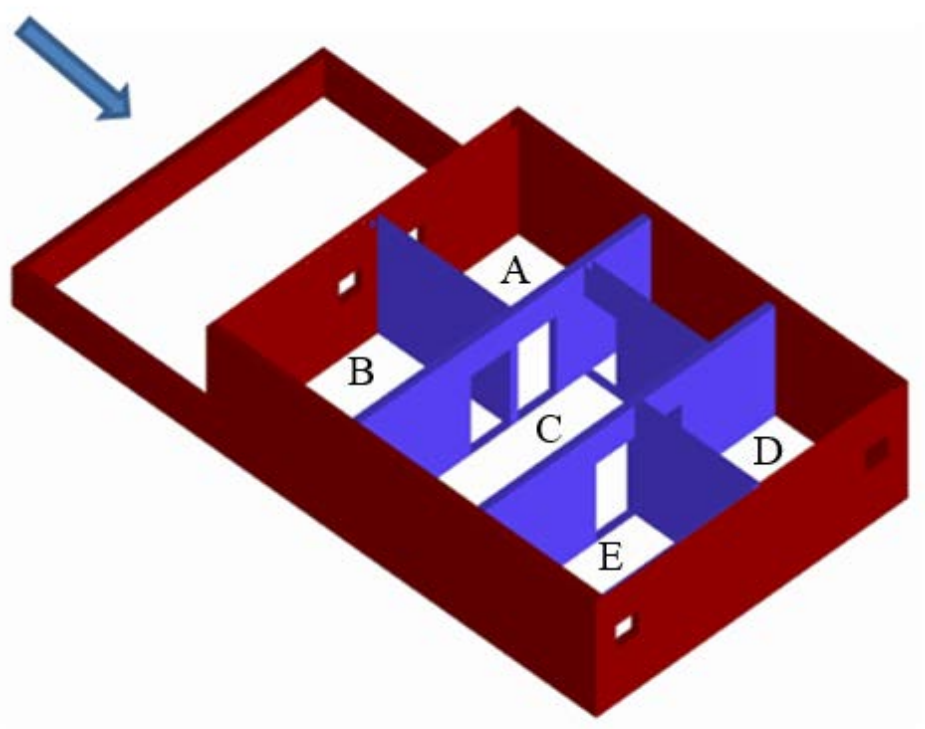

Fig. 1. Schema of the case used in the study.

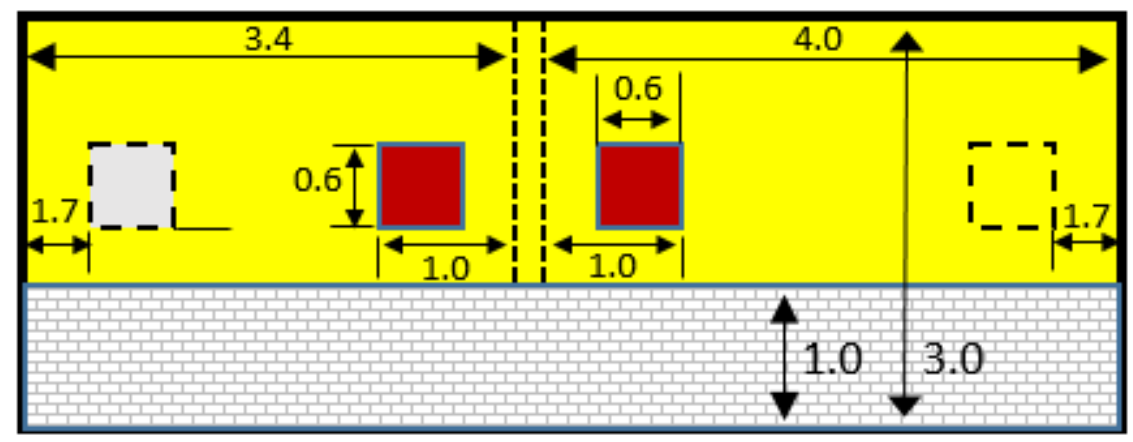

Fig. 2. Front view of the building with opening sizes and dimensions (m).

\section{Computational domain and grid}

The computational domain of this study followed the recommendation of the European Cooperation in Science and Technology (COST) [46] and the Architectural Institute of Japan (AIJ) [47] guidelines. The building was set inside a duct $(23.3 \times 5 \times 12.6) \mathrm{H}$, as shown in Fig. 3 and the 
blockage ratio was $4.2 \%$ which is within the range recommended in the guidelines. These guidelines suggest at least $5 \mathrm{H}$ as a distance between the inflow boundary and the building, whereas $15 \mathrm{H}$ was set as a distance between the outflow boundary and the building, which is enough to allow the flow to redevelop in the wake region. The numerical grid used for the basic case examined consists of around $6 \times 10^{6}$ hexahedral computational cells. A fine mesh was structured near the walls, while coarse mesh was used away from the walls in all directions. The $\mathrm{Y}^{+}$used for the first cell near the wall was 1.4, which was enough to capture a laminar sub-layer and the minimum grid spacing used in the present computations was $0.005 \mathrm{H}$ in all directions with a nonuniform grid of stretching ratio of 1.15-1.20.

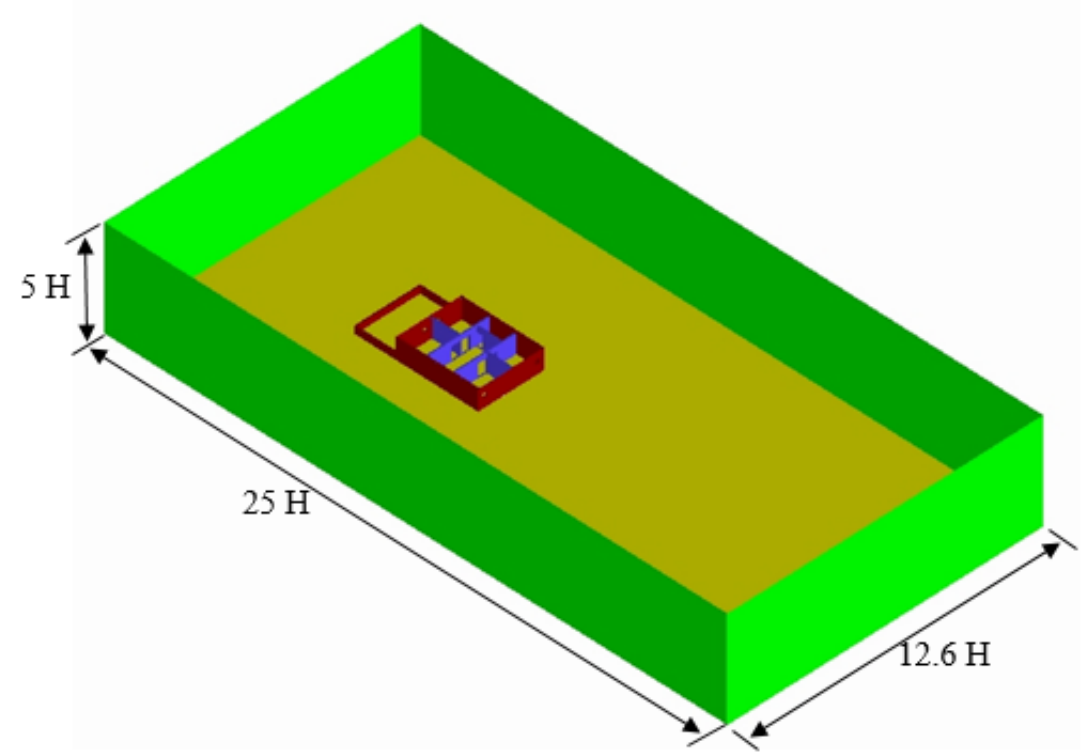

Fig. 3. The building inside a duct. 

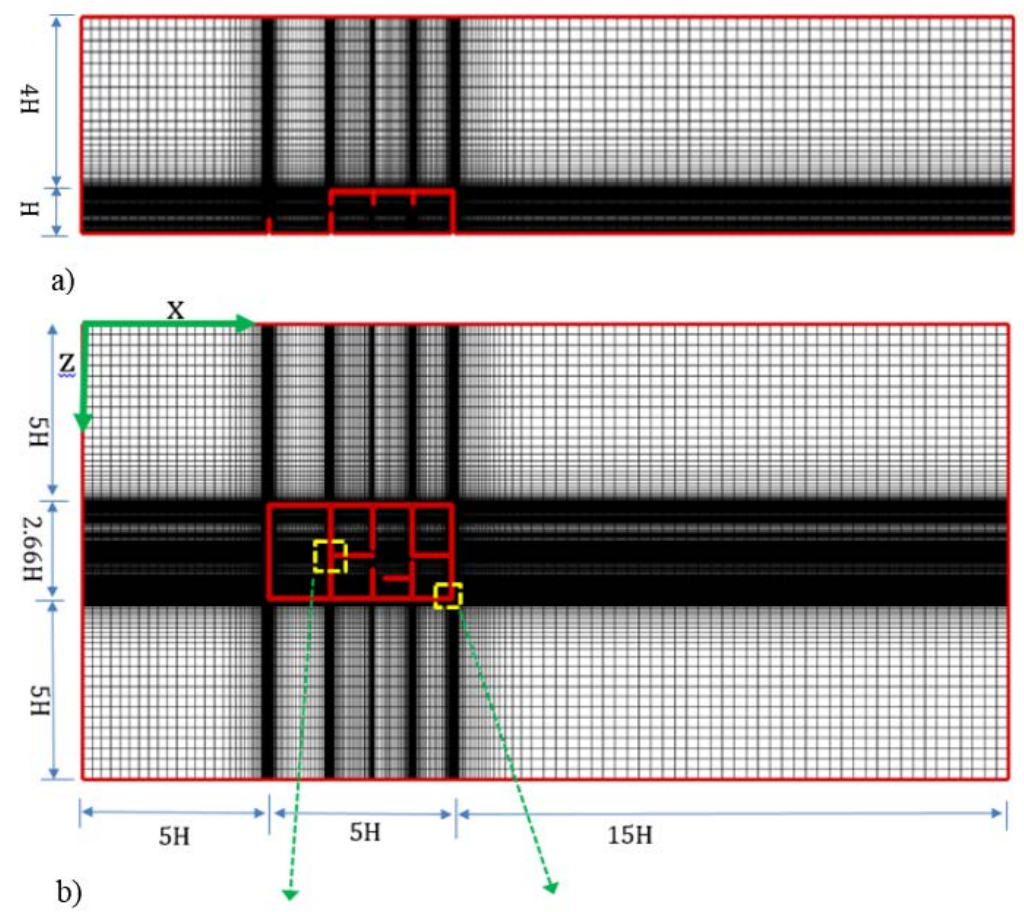

b)
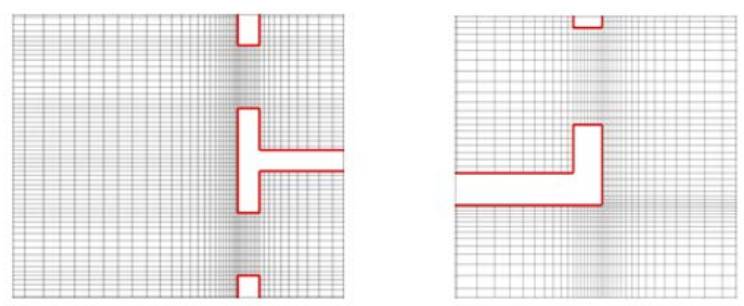

Fig. 4. Computational domain and the mesh layout of grid: (a) Side view, (b) Top view.

In this study, the method proposed by Celik et al. [48] was used to test the grid independence which depends on turbulent kinetic energy calculation. According to this method, the ratio of resolved kinetic energy to total kinetic energy is represented by the LES index as in Eq. 8. The total kinetic energy $\left(\mathrm{k}_{\mathrm{t}}\right)$ can be decomposed into the resolved part $\left(\mathrm{k}_{\mathrm{res}}\right)$ which is calculated from the numerical results, the contribution of the subgrid-scale model $\left(\mathrm{k}_{\mathrm{sgs}}\right)$, and the contribution of the numerical dissipation ( $\left.\mathrm{k}_{\text {num }}\right)$.

$$
L E S \_I Q=\frac{k_{r e s}}{k_{t}}=\frac{k_{r e s}}{k_{\text {res }}+k_{\text {sgs }}+k_{\text {num }}}=1-\frac{k_{t}-k_{\text {res }}}{k_{t}}
$$

the combined turbulent kinetic energy of numerical dissipation and subgrid-scale model based on 
Richardson extrapolation is assumed to scale with grid size/filter length, and further details can be found in [48]:

$$
k_{t}-k_{r e s}=a_{k} \Delta^{n}
$$

where $\mathrm{a}_{\mathrm{k}}$ is a coefficient that can be determined by running the LES on two grids with different resolutions, $\mathrm{n}=2$ is the order of accuracy of the numerical scheme.

Two grids were chosen by increasing the resolution with about a factor of 2, from Grid A $\left(3.5 \times 10^{6}\right)$ cells to Grid B $\left(6 \times 10^{6}\right)$ cells. The results obtained from the two grids are compared as profiles of LES_IQ along lines x/H = 4, 10 and 15 and are shown in Fig. 5. Grid B resolved more than $84 \%$ of turbulent kinetic energy and this is considered well-resolved according to Pop [49] which proposed a value of $80 \%$ at least, whereas Grid A resolved between $59-71 \%$ of turbulent kinetic energy.

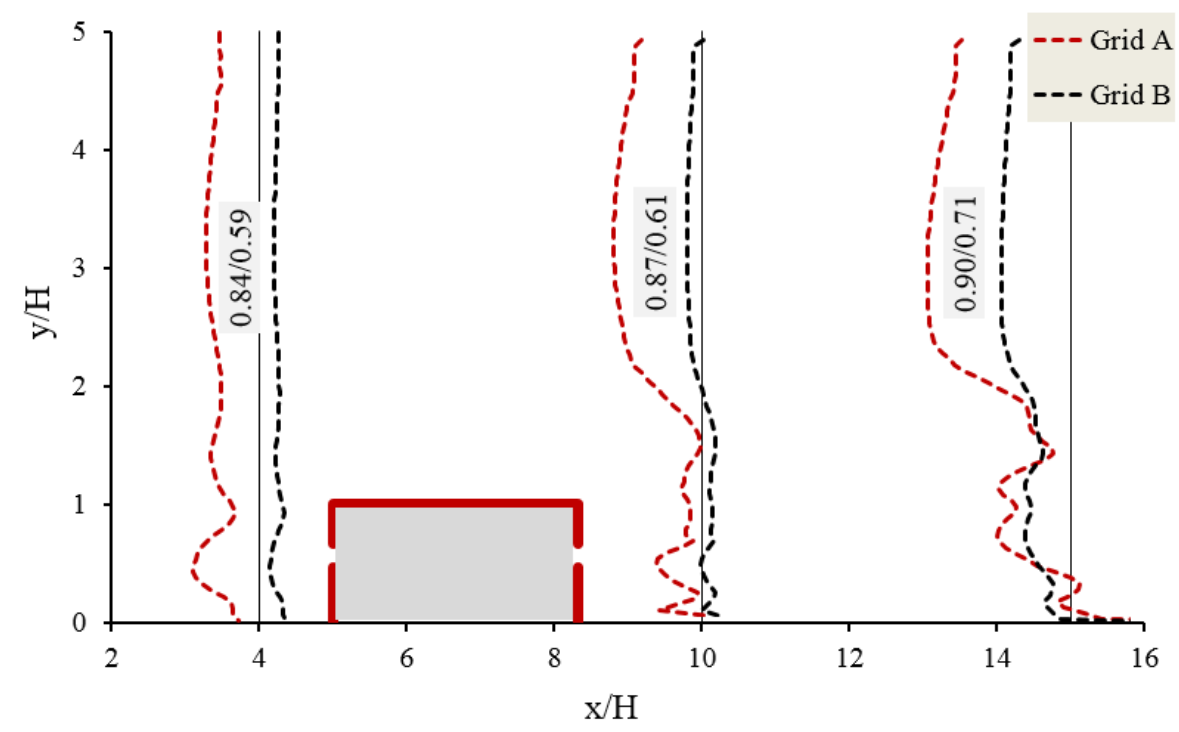

Fig. 5. Profiles of LES_IQ for Grid A and Grid B in the vertical lines for the basic case. 


\section{Boundary conditions and solver setting}

At the inlet of the domain, the vertical approach flow profiles of mean wind speed, turbulent kinetic energy, and specific dissipation rate were applied [50] and specified with Eqs. (10) - (12). The airflow was perpendicular to the windward building face and the logarithmic law was used as proposed by Richards and Hoxey [50]. The equations of turbulent kinetic energy and specific dissipation rate equations were applied successfully in the previous study [24-25].

$$
\begin{aligned}
& U(y)=\frac{u_{\tau}}{K} \ln \left(\frac{y+y_{o}}{y_{o}}\right) \\
& k=1.5\left(U I_{u}\right)^{2} \\
& \varepsilon=\frac{u_{\tau}{ }^{3}}{K\left(y+y_{o}\right)}
\end{aligned}
$$

The value of $u_{\tau}$ is determined based on the values of the reference velocity $\left(\mathrm{U}_{\text {ref }}=7 \mathrm{~m} / \mathrm{s}\right)$ at building height $(\mathrm{H})$. A time-dependent inlet profile is generated by using the vortex method with the number of vortices $\mathrm{N}=190$, and this setting was successfully tested in the previous LES validation studies for wind flows around buildings [51-53]. The surfaces of the house and the ground of the domain were modelled as a no-slip boundary, and at the outlet of the domain the zero-gradient condition was used [54]. The side and the top of the domain were modelled as symmetry conditions, i.e. zero normal velocity and normal gradients of all variables.

The CFD simulations were performed using the commercial CFD package, FLUENT R16.3 [40]. For incompressible flow the pressure based solver was used in this study. The PISO algorithm was used for the pressure-velocity coupling, and a second-order discretization scheme was used for the pressure interpolation. To discretize the convection term in the filtered momentum equation, the bounded central-difference scheme was applied. Time discretization was secondorder implicit and the non-iterative scheme was used for the time advancement. This scheme 
allows for an inner iteration to solve the individual set of equations instead of single outer iteration per time-step, which significantly speeds up the transient simulations [40]. Courant FriedrichLewy (CFL) condition less than 1 was used to calculate the time step required to perform the simulations and was applied to incompressible flow in previous studies [51, 55-56]. The time step was determined according to the maximum number of the Courant-Friedrich-Lewy (CFL) to avoid any numerical instability. In this simulation, the maximum CFL was less than 0.6 when $\Delta \mathrm{t}$ was set

to $7.5 \times 10^{-6} \mathrm{~s}$. To ensure a steady state was reached, the transient run continued for a sufficiently long period of time (5 times the flow through-time). In addition, the convergence of RMS quantities in unsteady flow was used to check the steady-state convergence.

\section{Model validation}

In order to demonstrate the accuracy of the LES simulation, a comparison between the simulation results and the available experimental results was performed. The details of the validation case were presented in the reference by Ohba et al. [57]. The experiment was conducted in a wind tunnel, $1.2 \mathrm{~m}$ wide, $1.0 \mathrm{~m}$ high and $14.0 \mathrm{~m}$ long, and the model case had the dimensions $(1 \times 2 \times 2) \mathrm{H}$, where $\mathrm{H}$ represents the height of the building $(15 \mathrm{~cm})$. Both openings were equal in dimension $(0.4 \times 0.2) \mathrm{H}$ and located at the centre of the front and rear walls of the building. The wind speed at the building height was $7 \mathrm{~m} / \mathrm{s}$ and the vertical profile of time-average velocity $\mathrm{U}(\mathrm{y})$ were compared between the LES and the experiment in Fig. 6. The figure shows some deviation between the two profiles at the upper level of the domain near the inlet but the agreement between them at the lower level of the building was satisfactory. The LES simulation predicted close results to those of the experiment regarding the pressure coefficients along the centreline of the windward and leeward of the building and regarding the vertical mean velocity at mid-height of the openings, 
as shown in Fig. 7. In addition, a comparison of the mean pressure coefficient on faces of the building obtained from the present study and the previous studies is shown in table 2 . It is obvious that the calculated pressure coefficient is in the range of the previous reported values [58, 59].

Table 2

Comparison of mean pressure coefficient.

\begin{tabular}{llll}
\hline & Top surface & Front surface & Rear surface \\
\hline Jiang [58] and Evola and & -0.2 to -0.52 & 0.56 to 0.7 & -0.15 to -0.35 \\
Popov [59] & & & \\
Present (LES) & -0.57 & 0.56 & -0.32
\end{tabular}

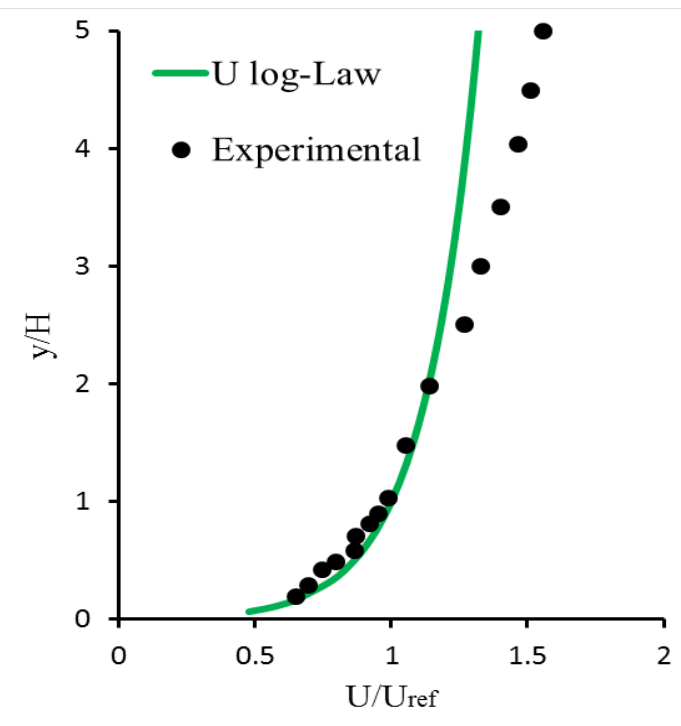

Fig. 6. Comparison of mean velocity profiles of the approaching wind with experimental [57] at the inlet of the duct. 
a)

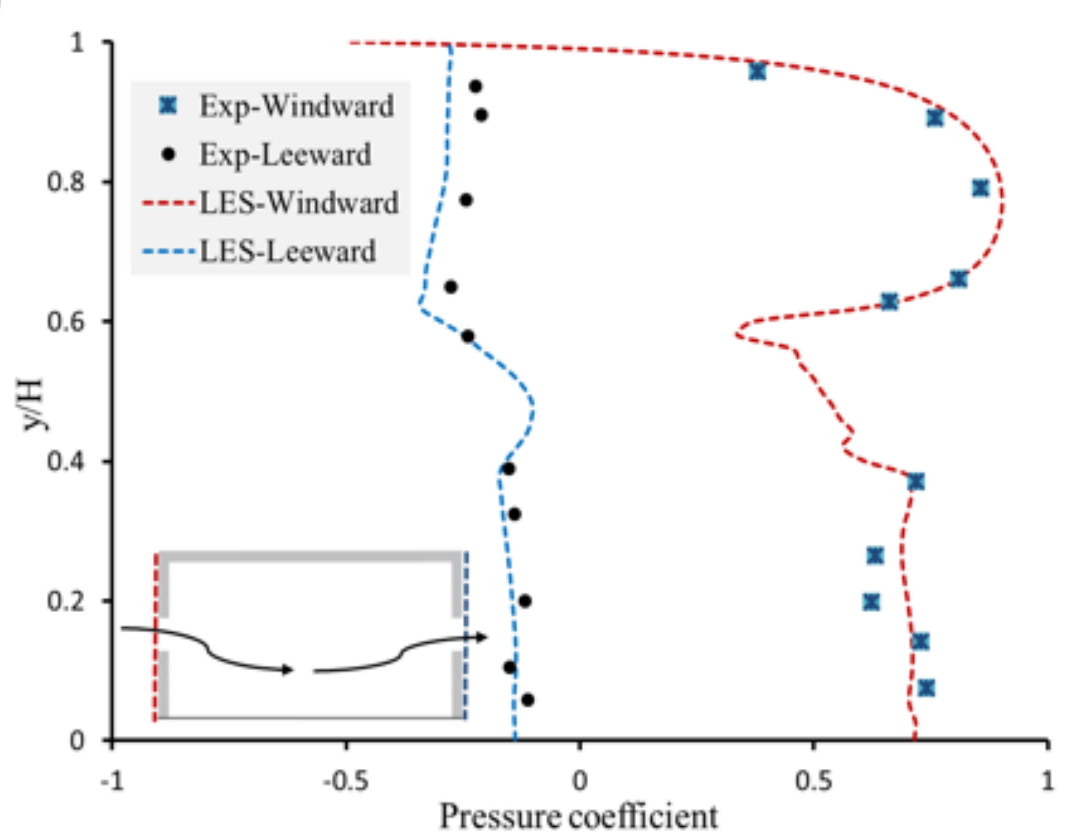

b)

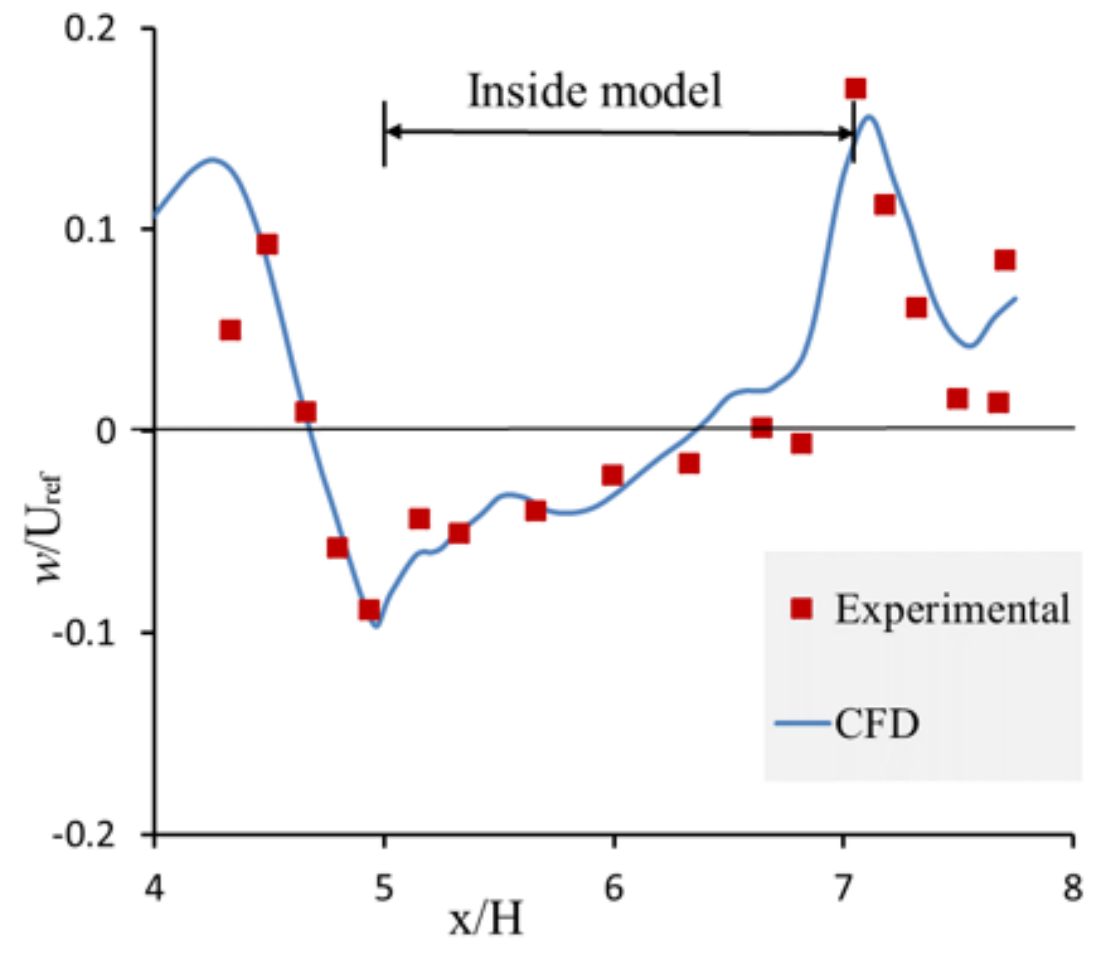

Fig. 7. Comparison between the LES and experiment results [57]: a) pressure coefficient; b) vertical mean velocity at mid-height of the openings. 


\section{Results and discussion}

As defined in section 3, this study investigated the effect of an external boundary wall on the natural cross-ventilation of a small scale family house. Three different configurations of the models (basic case without a wall, and two cases with a wall) were used to examine the effects of an external boundary wall and its height on the recirculation area, flow pattern and the rate of ventilation inside the building, in order to determine the wind comfort of the occupants. The external boundary wall located in front of the building and the inner layout of the building was kept the same for the three configurations, and the schema of each case is shown in Figs. 1-2. The flow entered from two openings on the front wall and exited from two openings on the rear wall of the house. The areas of the openings were kept constant in all cases and the wind speed also remained constant at $7 \mathrm{~m} / \mathrm{s}$ with wind incidence angle of $0^{\circ}$.

\subsection{Mean flow and streamlines around the building}

The mean velocity and streamlines around the building for all cases are shown in Figs. 8 and 9 on the vertical and horizontal planes respectively. These figures show that an external wall has significant impact on the behaviour of flow around the building and this effect will extend to inside the building, changing the flow patterns and circulation zones inside the rooms. Regarding Case-EF and Case-EFH, the boundary wall caused a significant reduction in the mean pressure in front of the openings as shown in Fig. 10, subsequently forming a large circulation zone. When the height of the wall increased by $20 \%$, the mean pressure also reduced and the circulation zone became larger and more intensive, whereas a small circulation near the ground formed in the absence of a wall (the basic case).

The large circulation in the presence of the wall reduced the mean x-velocity for two inlet openings considerably from $3.65 \mathrm{~m} / \mathrm{s}$ in the basic case to $1.92 \mathrm{~m} / \mathrm{s}$ in Case-EF and 1.24 in Case- 
$\mathrm{EFH}$, whereas the mean y-velocity magnitude increased from 0.07 in Case-I to 3.4 in the other cases which had the main function of reducing the mean flow velocity inside the building (Table 3). This is because the flow was diverted upwards by the wall and then swept to the ground. The kidney shape vortex which covered one-third of the length of the building roof in the basic case almost disappeared and caused the flow slipping on the roof of the building. The upstream flow accelerated when it struck the edges of the roof, reaching a maximum velocity of $9.1 \mathrm{~m} / \mathrm{s}$ in the basic case and reduced to 8.6 and $8.4 \mathrm{~m} / \mathrm{s}$ for Case-EF and Case-EFH respectively.

\subsection{Mean flow patterns inside the building}

Figure 11 presents the mean airflow velocity magnitude contours in a horizontal plane passing through the middle of the openings which is assumed to be user level. In addition, the profiles of mean velocity from the centre of the openings to the end of the building are provided in Fig.12. Regarding Case-I, the high velocity (the red area) near the inner walls in rooms A, B and C had a direct impact on the indoor discomfort and it would be difficult for a designer to provide proper thermal distribution inside these rooms. In the other two cases the mean velocity was considerably reduced to less than $0.3 \mathrm{~m} / \mathrm{s}$ (the blue area) in most areas of all rooms and the difference between the front and rear rooms was small, therefore these two configurations could make it easier for a designer to attain proper thermal distribution than the basic case. In addition, figure 12 shows that the airflow mean velocity in Case-I declined sharply to $0.5 \mathrm{~m} / \mathrm{s}$ at the end of the building by two steps, whereas in the other two cases the velocity dropped to less than $0.5 \mathrm{~m} / \mathrm{s}$ directly after passing the openings and stayed at the same level along the building. It can be concluded, therefore, that adding a boundary wall can improve the indoor environment considerably in terms of indoor airflow velocity. The figure also shows that increasing the height of the wall does not make any significant difference to the distribution of mean velocity in the rooms. 


\subsection{Streamlines inside the building}

Figure 13 presents the mean streamlines of the airflow at the horizontal plane crossing the middle of the inlet openings. The three cases showed almost the same pattern, a recirculation zone formed in each room for all cases, especially in rooms A and B, in which the flow enters the house directly through the two openings, while the recirculation is weaker in rooms D and E. The strong circulation inside rooms A and B is due to the high-velocity flow and intensity and the results of all cases show that the recirculation zone in room $\mathrm{A}$ is stronger than that in room B due to the fact that room B is smaller than room A. The horizontal plane figure showed that the streamlines of the flow in both cases are normal to the openings, producing two circulation zones in opposite directions (clockwise in room B and counter clockwise in room A) while the vertical section (Fig. 10) presents different patterns between Case-EF and Case-EFH on the one hand and Case-I on the

other hand. The flow enters in straight lines parallel to the ground in Case-I, forming a small circulation at a high level in the rooms while in the other two cases the flow enters the openings with an angle of $45^{\circ}$, producing a large double circulation between the front rooms (A and B) and the middle room (C). The circulation provides good air mixing inside the building. The circulation inside the building became larger when the height of the wall is increased, which means that the formed circulation has a strong relation with the height of the boundary wall.

\subsection{Fluctuating ventilation rate}

An indication of the transient nature of the predicted flow through the two windward openings is given in Fig. 14 for the three cases, where the dimensionless ventilation rate $\mathrm{Q}^{*}$ based on reference velocity (Uref $=7 \mathrm{~m} / \mathrm{s})$ is defined as:

$$
\mathrm{Q}^{*}=\mathrm{Q} / \mathrm{U}_{\text {ref }} \mathrm{A}
$$

in which $\mathrm{A}$ is the opening area. If the design is based on the rate of ventilation, the comparison of 
openings' aeration flow will be very important. The standard deviation of the ventilation rate is used to indicate the fluctuation intensity of the instantaneous ventilation rate [36, 45]. Because the fluctuation of a wind-induced ventilation rate is caused by the turbulence impact of wind, the standard deviation of the flow rate through the openings can be considered to be turbulenceinduced ventilation rates [36, 60-61]. Thus, the ratio of standard deviation to dimensionless ventilation rate refers to the role of the turbulence-induced component in the total ventilation rate [60]. The figure shows that the standard deviation predicted at both openings of Case-EF and CaseEFH was higher than Case-I because the boundary wall increased the intensity near the openings, therefore the flow became more turbulent near the openings than Case-I. The standard deviation of the ventilation rates can be considered to be turbulence-induced since the fluctuation of a windinduced ventilation rate is caused by the turbulence impact of wind.

The figure shows that the ratios of standard deviation to the dimensionless ventilation rates of openings 1 and 2 for Case-EF and Case-EFH were about 53\% and 82\%, respectively, whereas for Case-I the ratio was small, around $22 \%$, for both openings. This means that the mean flow stream provides at least $78 \%$ of the total ventilation rate in Case-I, while in the other two cases the mean stream provides less than $47 \%$ and $18 \%$, respectively. In conclusion, the main source of momentum for the ventilation in Case-I was provided by the mean flow, while in the other two cases the turbulent flow provided a greater source of momentum than mean flow especially in Case-EFH with $82 \%$. Although the significant reduction in the ventilation rate was found to be between $33 \%$ and $52 \%$ of the case without a boundary wall, as shown in Fig. 15, the solid wall offered the advantage of enhancing the indoor environment and made the design easier, as explained in the previous section. In addition, the figure shows that the rate of ventilation is inversely proportional to the height of the boundary wall and decreased by $36 \%$ when the height 
was increased by $20 \%$. Therefore, the designer should be careful to set the height of the boundary wall in front of the building.

\subsection{Turbulent kinetic energy}

Figure 16 shows the horizontal plane at the centre of the openings with the distribution of the dimensionless turbulent kinetic energy $\mathrm{k}$ for all cases, which is calculated from the turbulent kinetic energy of the resolved scale and subgrid scale. Regarding Case-EF and Case-EFH, the simulation predicted higher $\mathrm{k}$ in front of the openings than that in the basic case, and the fluctuation of the flow at the openings increased as well. High fluctuation has a negative impact on the rate of ventilation, therefore, the ventilation rate decreases considerably when a wall is present, as shown in Fig. 15 [62]. On the other hand, the total indoor kinetic energy was reduced by around 20\% with the addition of the wall in Case-EF and 42\% in Case-EFH because of the lower flow rate through the openings, which has a proportional relationship with the indoor kinetic energy as discussed in

previous studies[34]. Therefore it can be concluded that any boundary wall in front of an opening can lead to a decrease in the airflow rate through the openings, and there will be lower fluctuation of indoor kinetic energy (Fig. 17). Therefore the wind comfort inside the building can be more easily achieved when the air has lower indoor kinetic energy. 

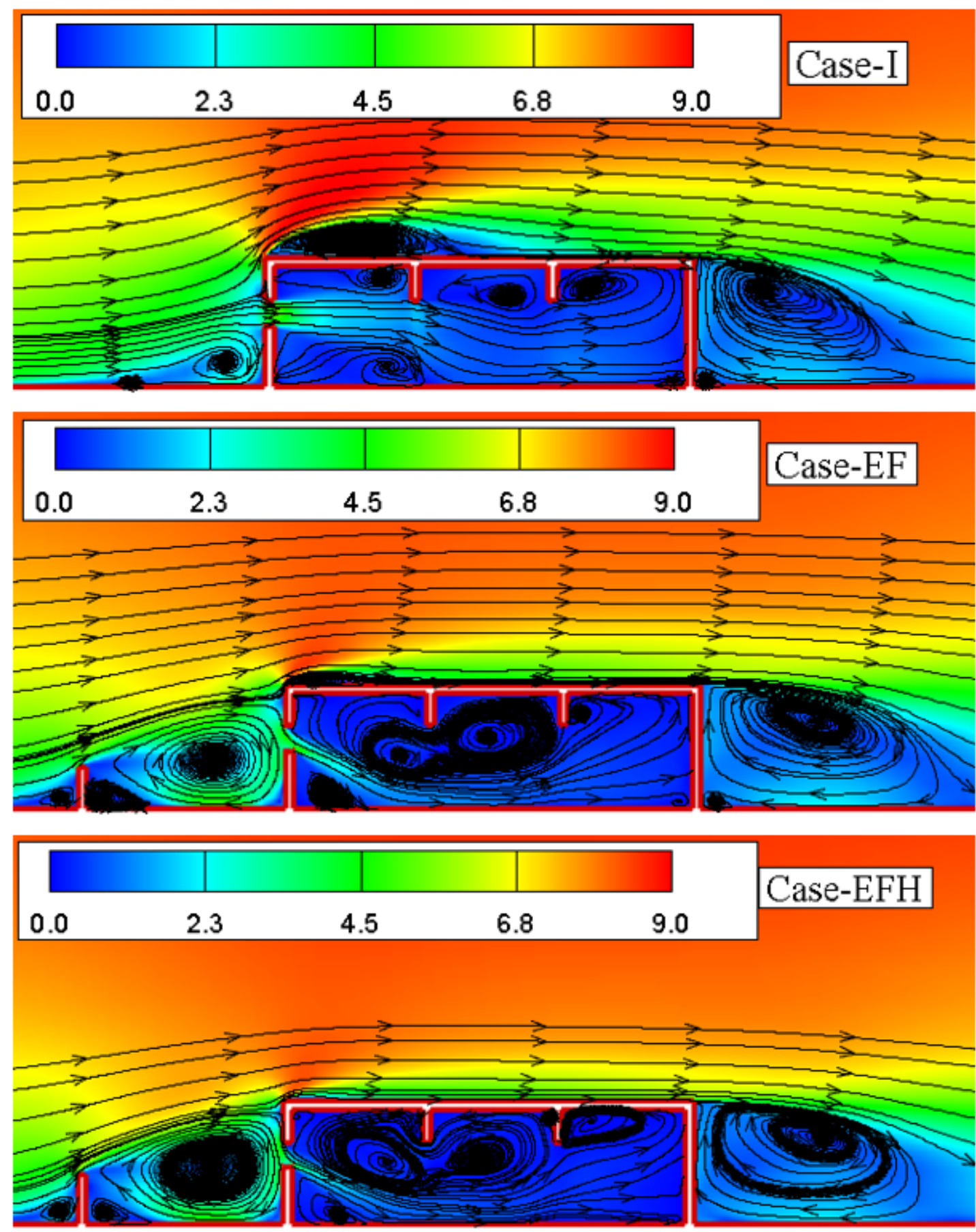

Fig. 8. Mean velocity $(\mathrm{m} / \mathrm{s})$ and streamlines inside and around the building in the vertical plan and passing middle of opening- 2 . 

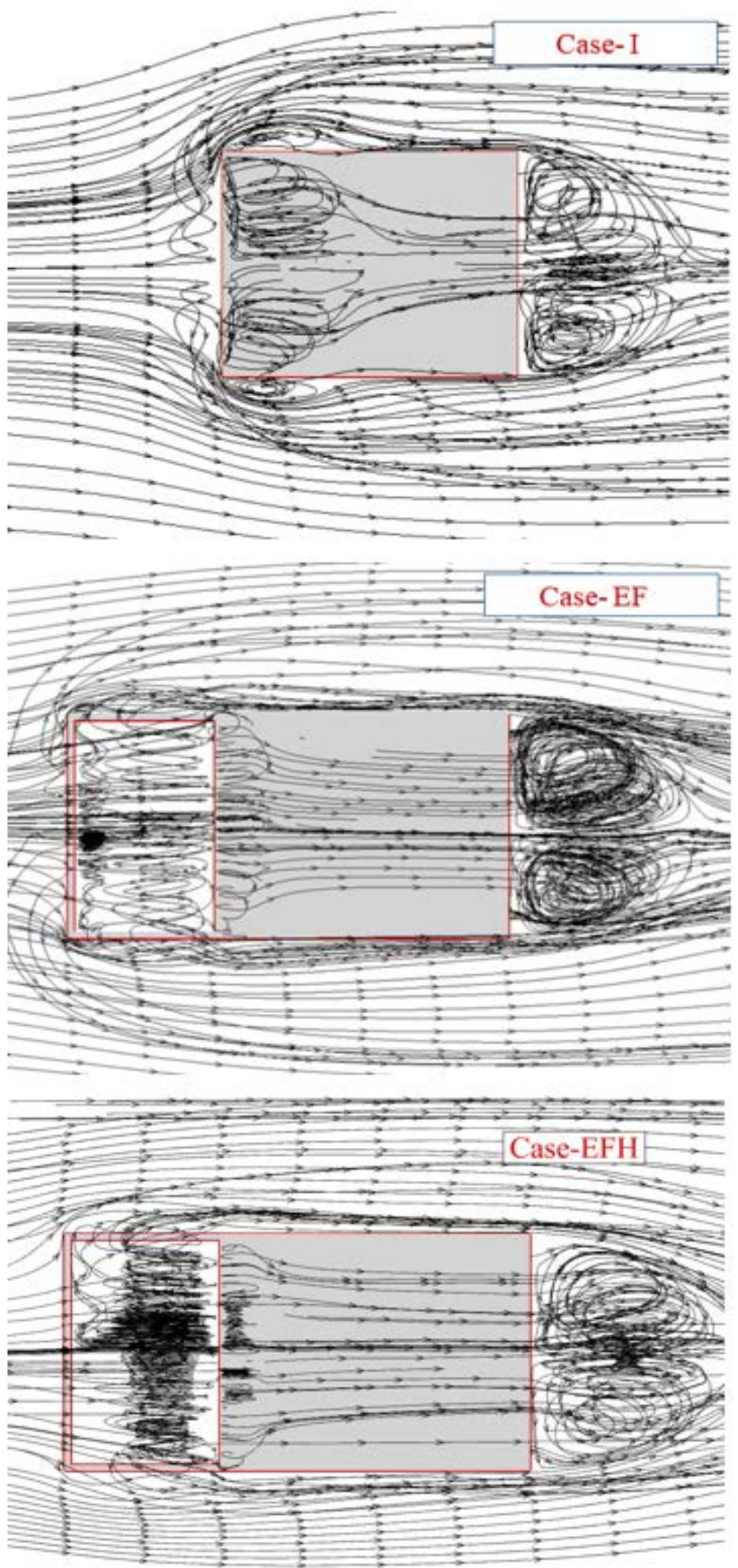

Fig. 9. Mean streamlines around the building in the horizontal plane $(\mathrm{y} / \mathrm{H}=0.56)$. 

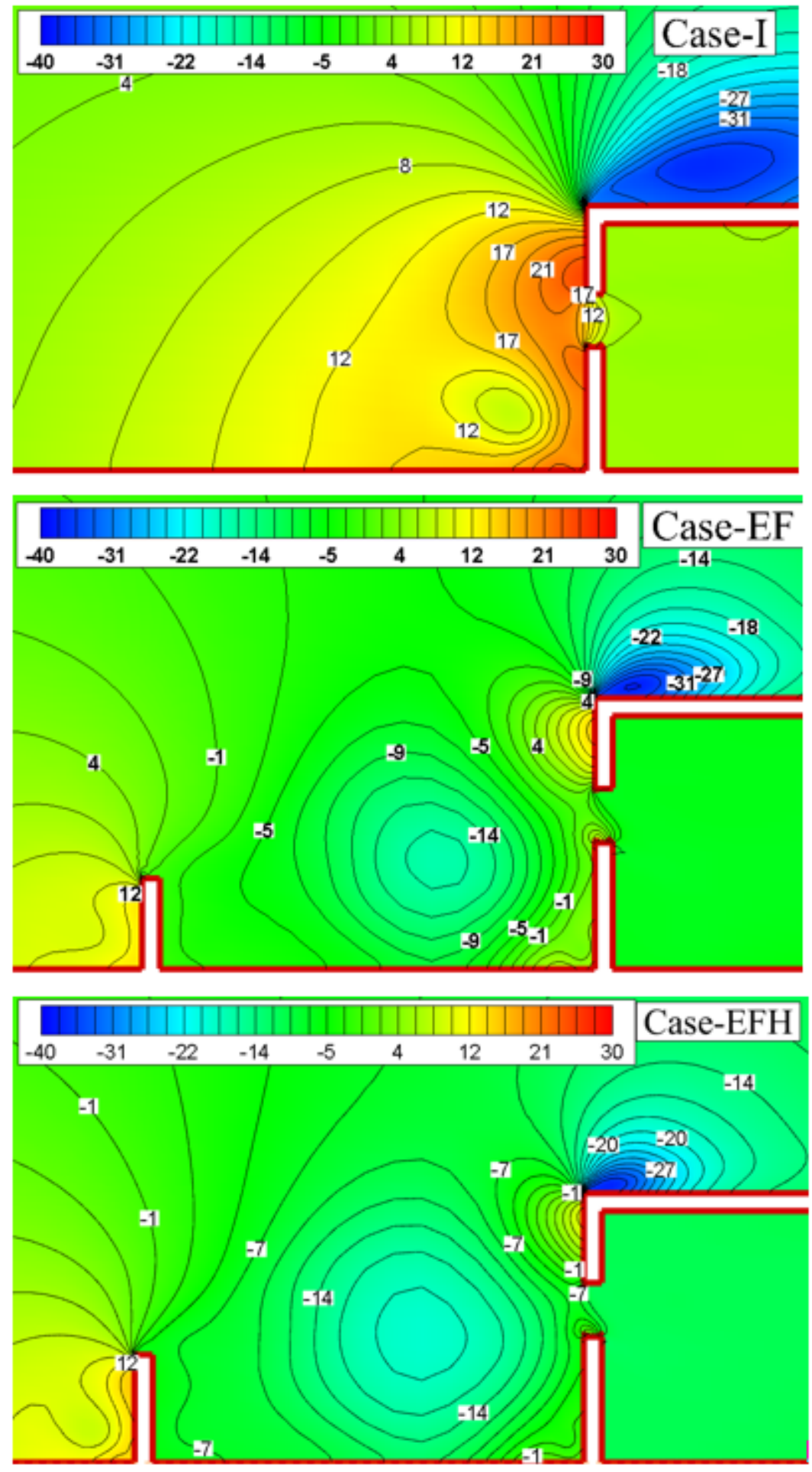

Fig. 10. Mean pressure contours in front of the building in the vertical plane and passing middle of opening-2. 

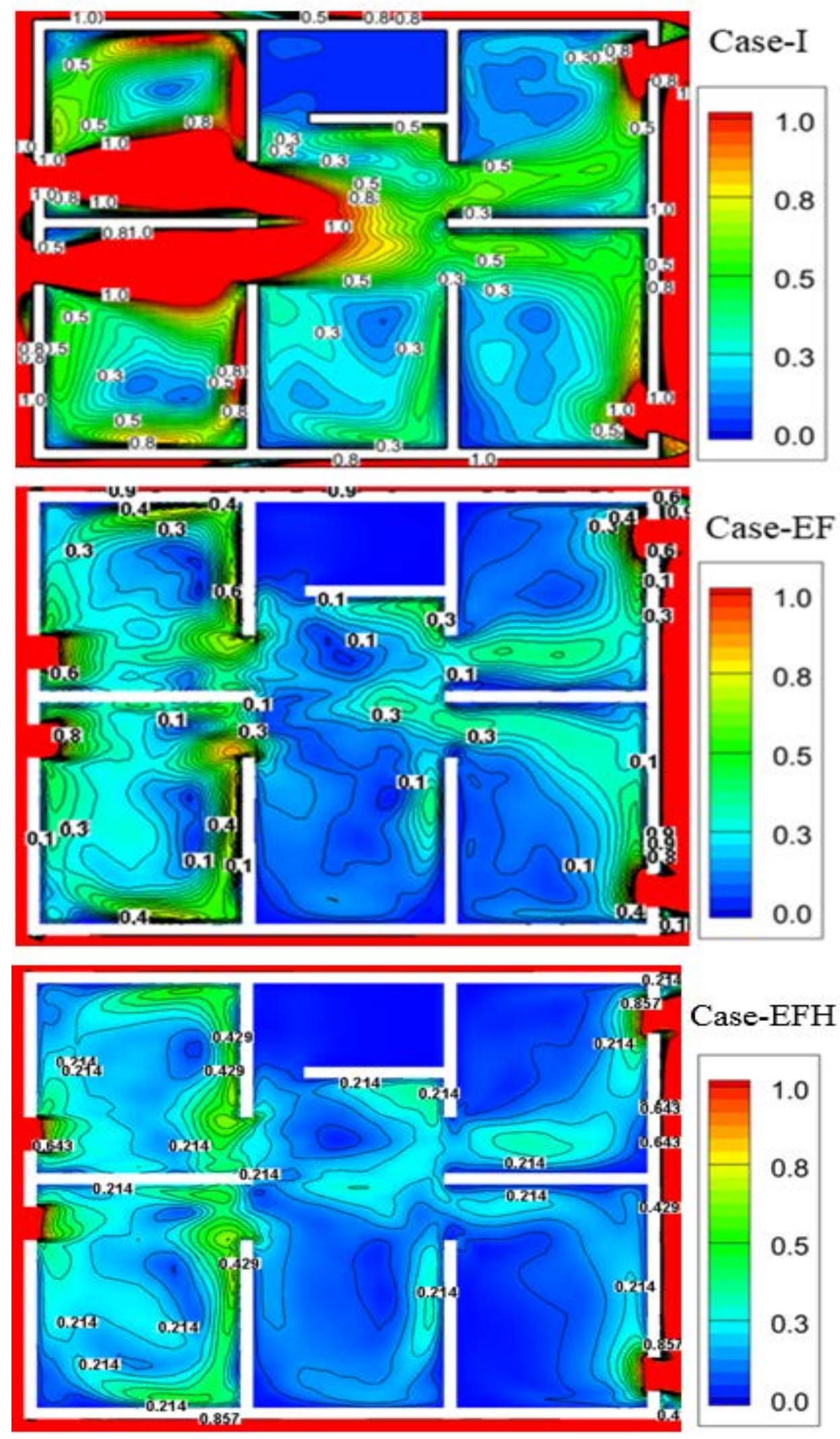

Fig. 11. Mean velocity contours $(\mathrm{m} / \mathrm{s})$ inside the building in the horizontal plane $(\mathrm{y} / \mathrm{H}=0.56)$. 


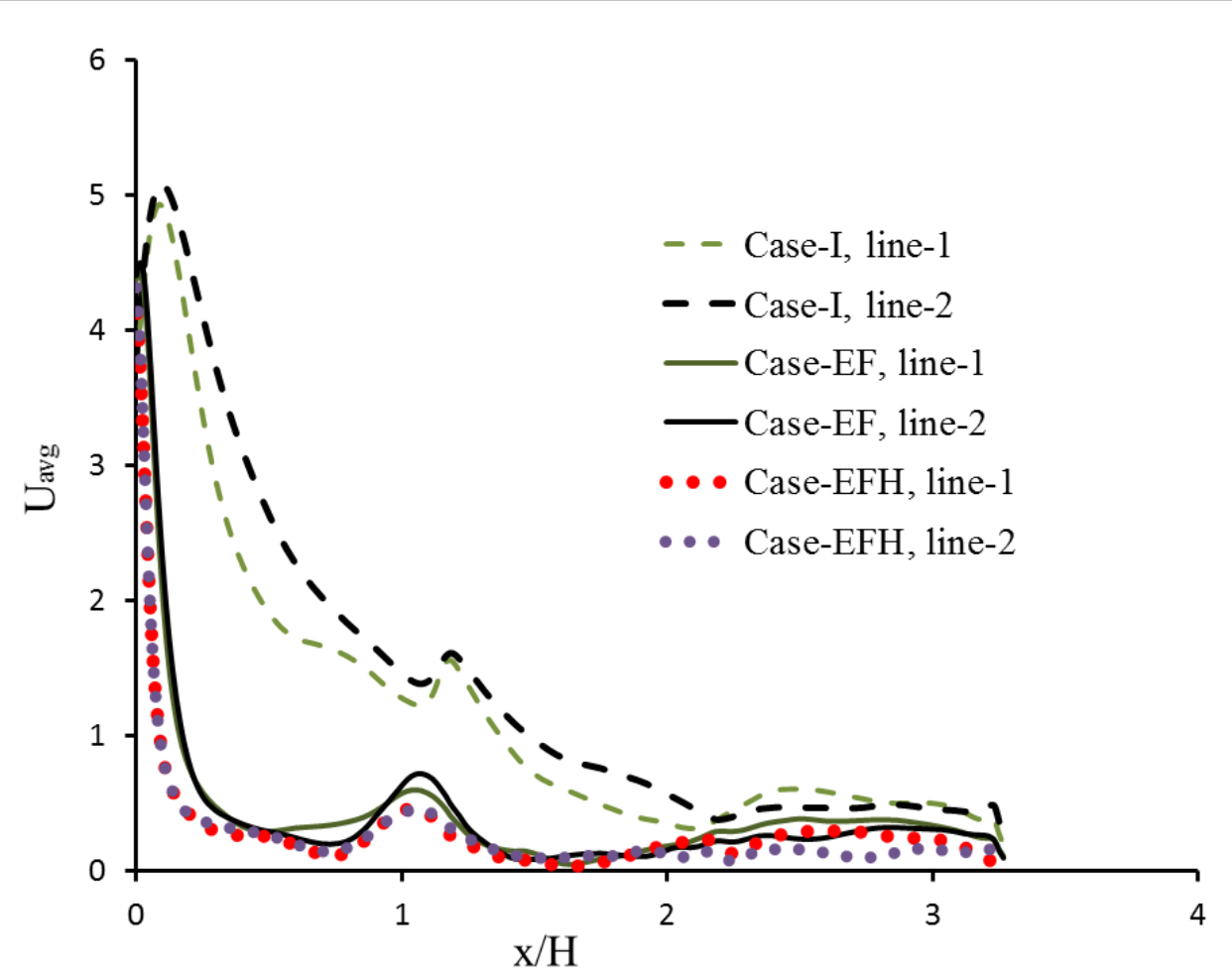

Fig. 12. Indoor average mean velocity (m/s) profile of lines along the building.

\section{Table 3}

Mean indoor velocity $(\mathrm{m} / \mathrm{s})$

\begin{tabular}{llcl}
\hline Cases study & X-velocity & y-velocity & z-velocity \\
\hline Case- I & 3.65 & -0.07 & -0.32 \\
Case-EF & 1.92 & -3.4 & -0.11 \\
Case-EFH & 1.24 & -3.4 & 0.03 \\
\hline
\end{tabular}



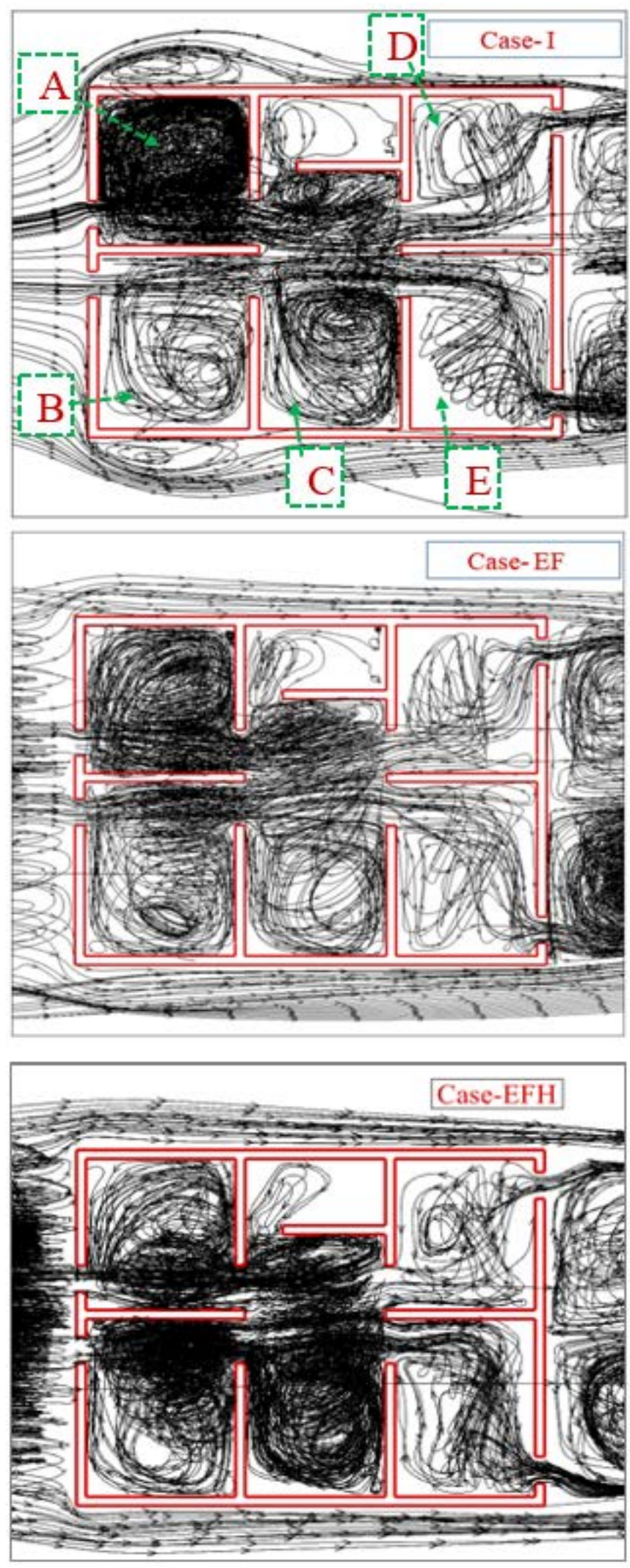

Fig. 13. Mean streamlines velocity in the horizontal plane $(\mathrm{y} / \mathrm{H}=0.56)$. 

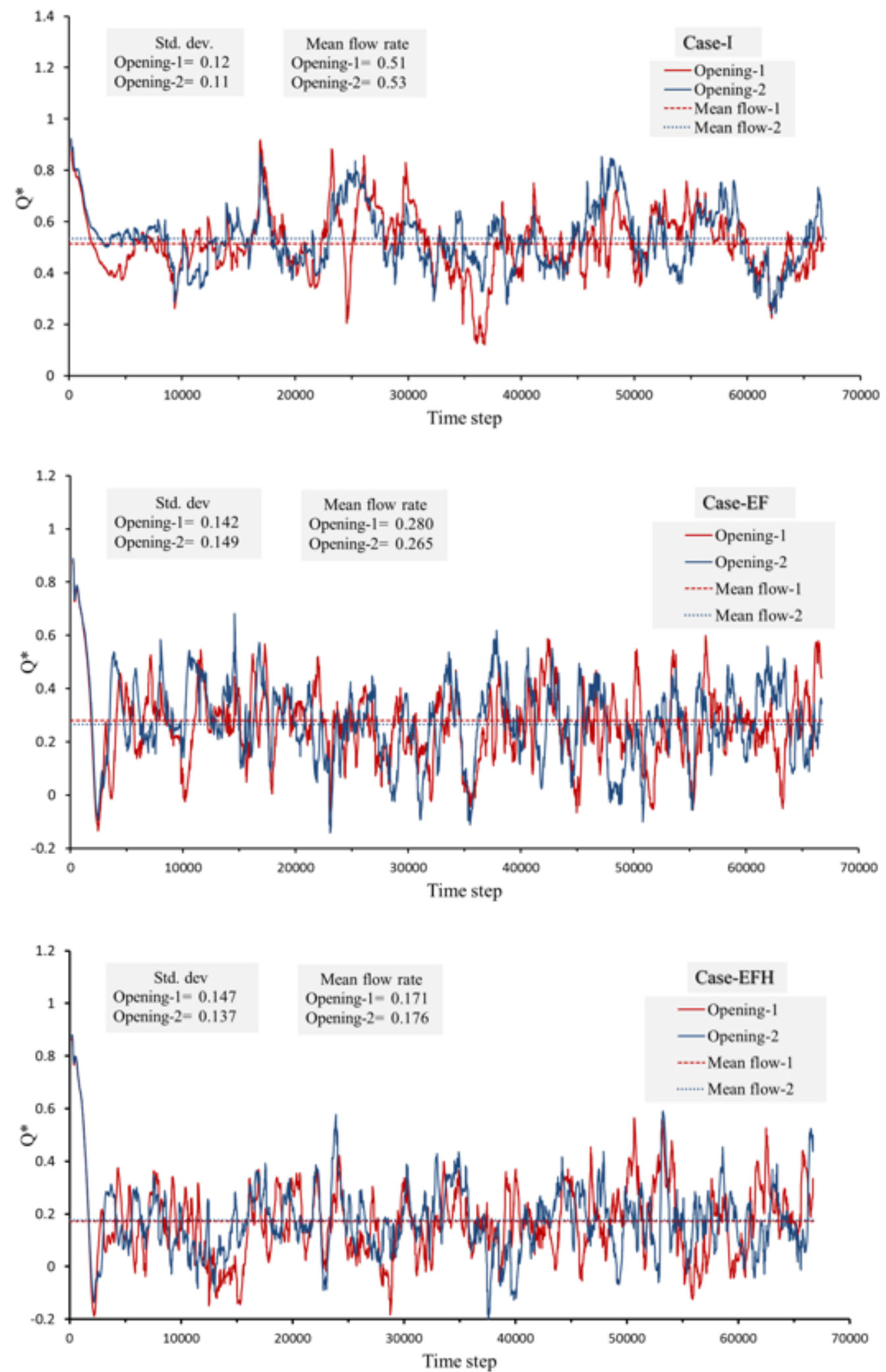

Fig. 14. Variation of the dimensionless ventilation rate over time steps. 


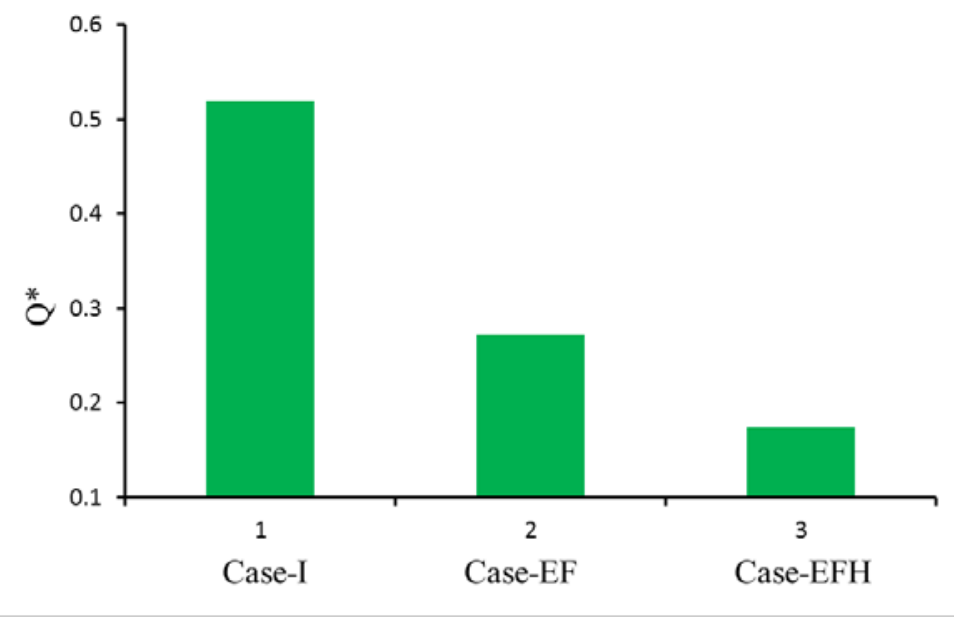

Fig. 15. Comparison of dimensionless ventilation rate. 


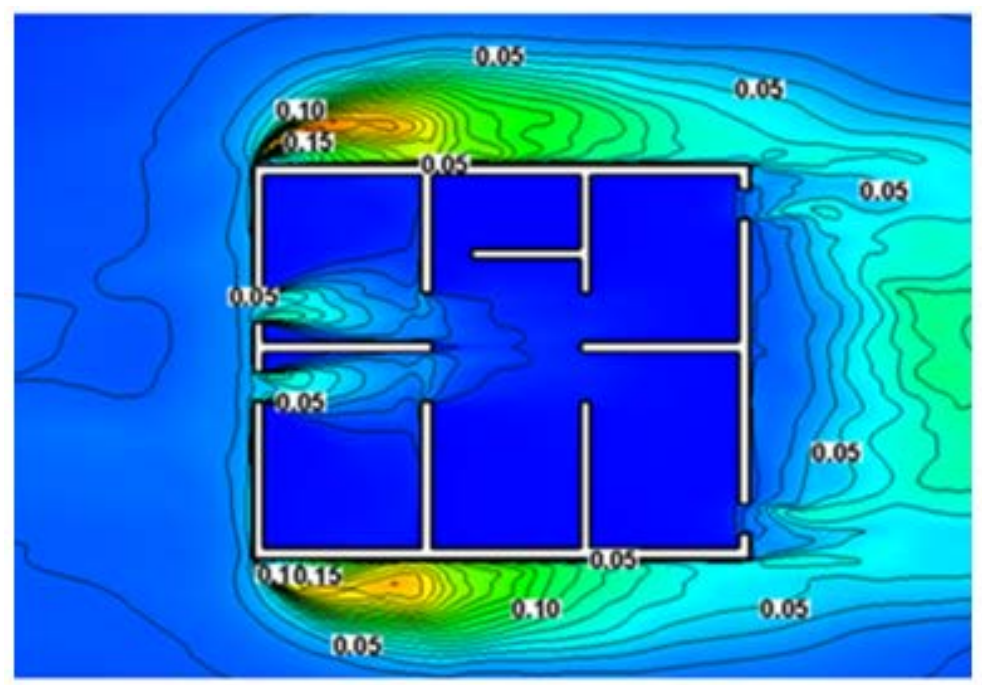

Case-I
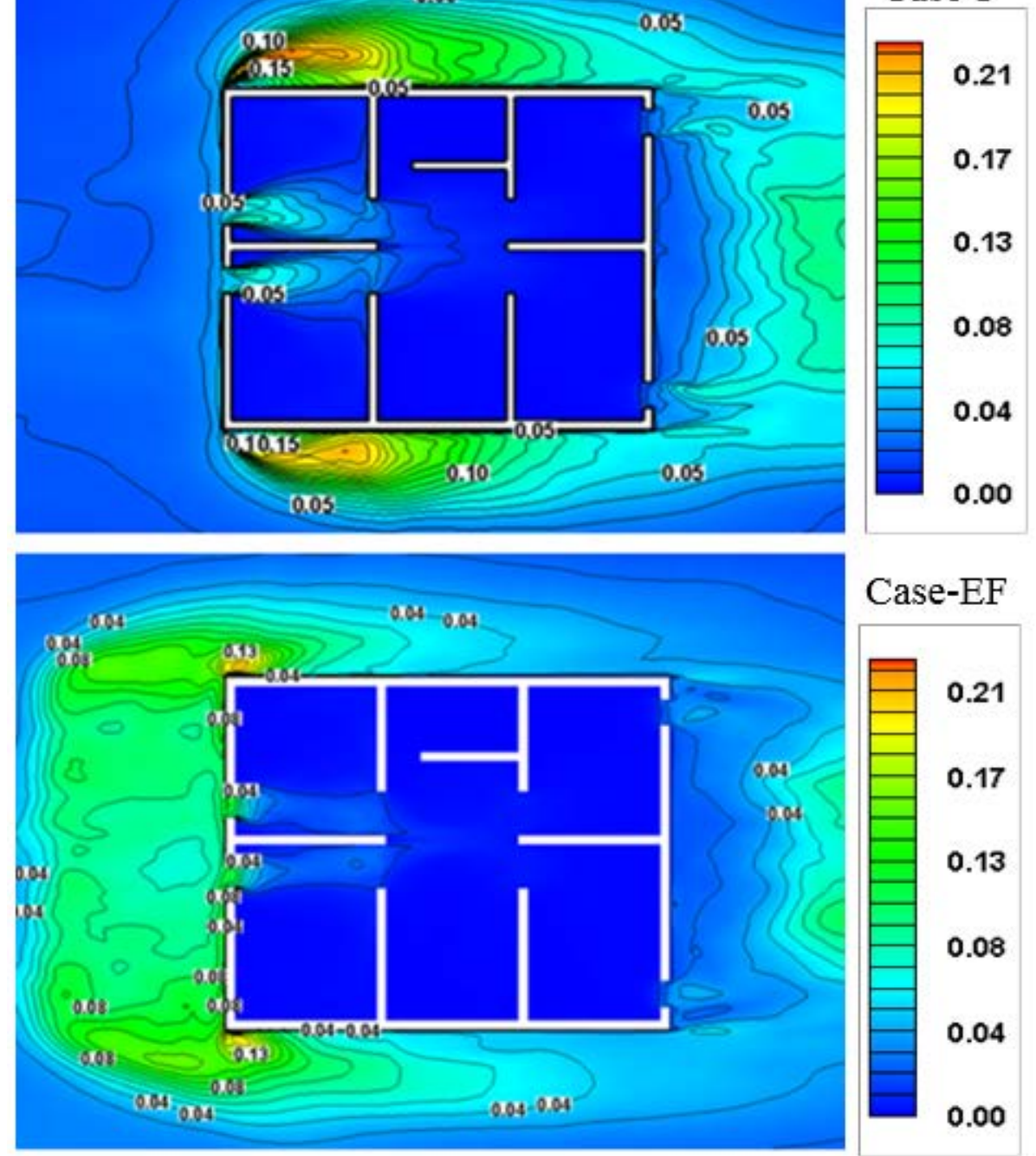

Case-EF
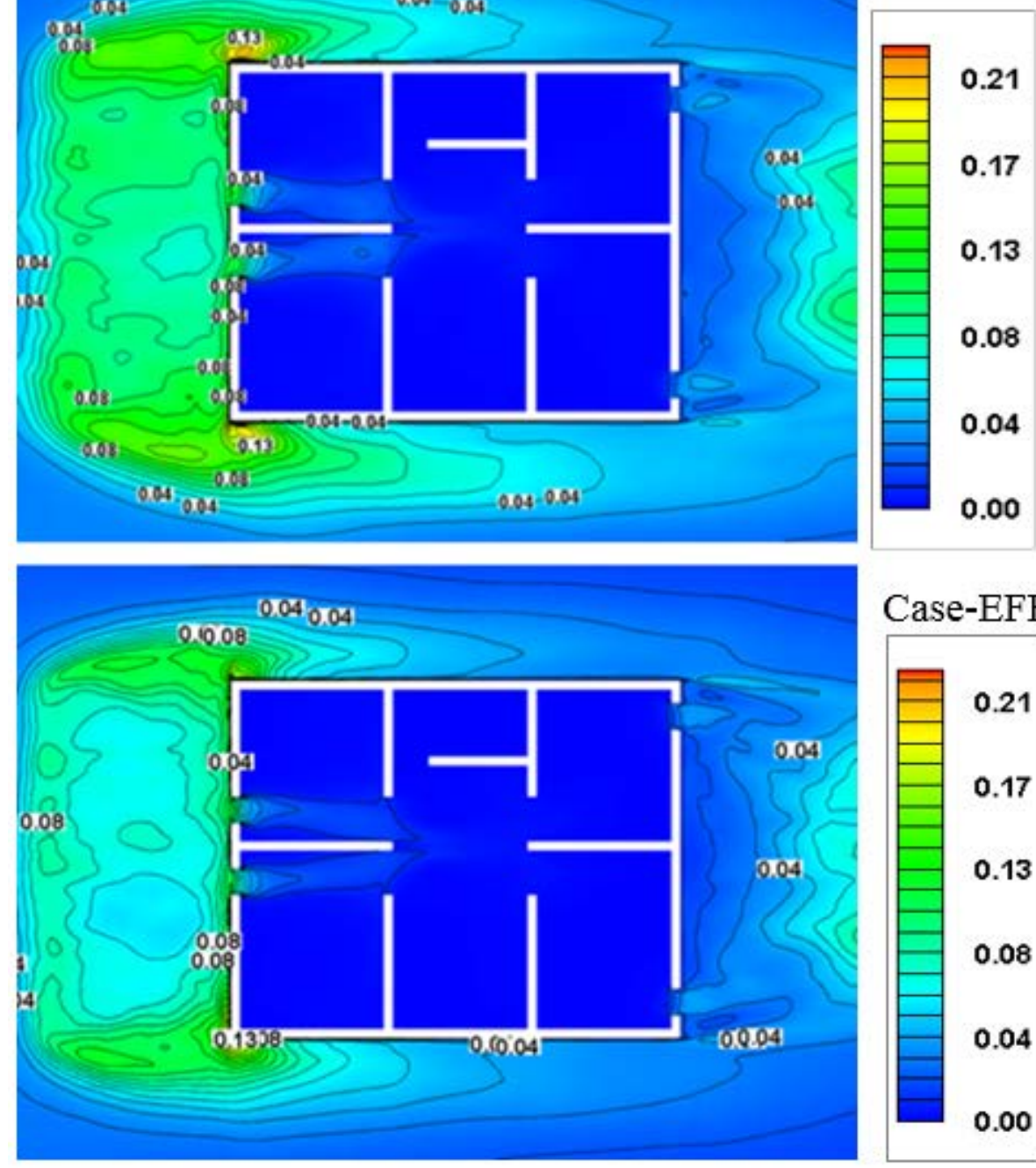

\section{Case-EFH}

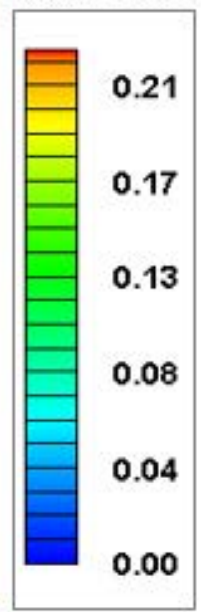

Fig. 16. Distribution of turbulent kinetic energy around the building $\left(\mathrm{k} / \mathrm{U}^{2} \mathrm{ref}\right)$ in the horizontal plane $(\mathrm{y} / \mathrm{H}=0.56)$. 

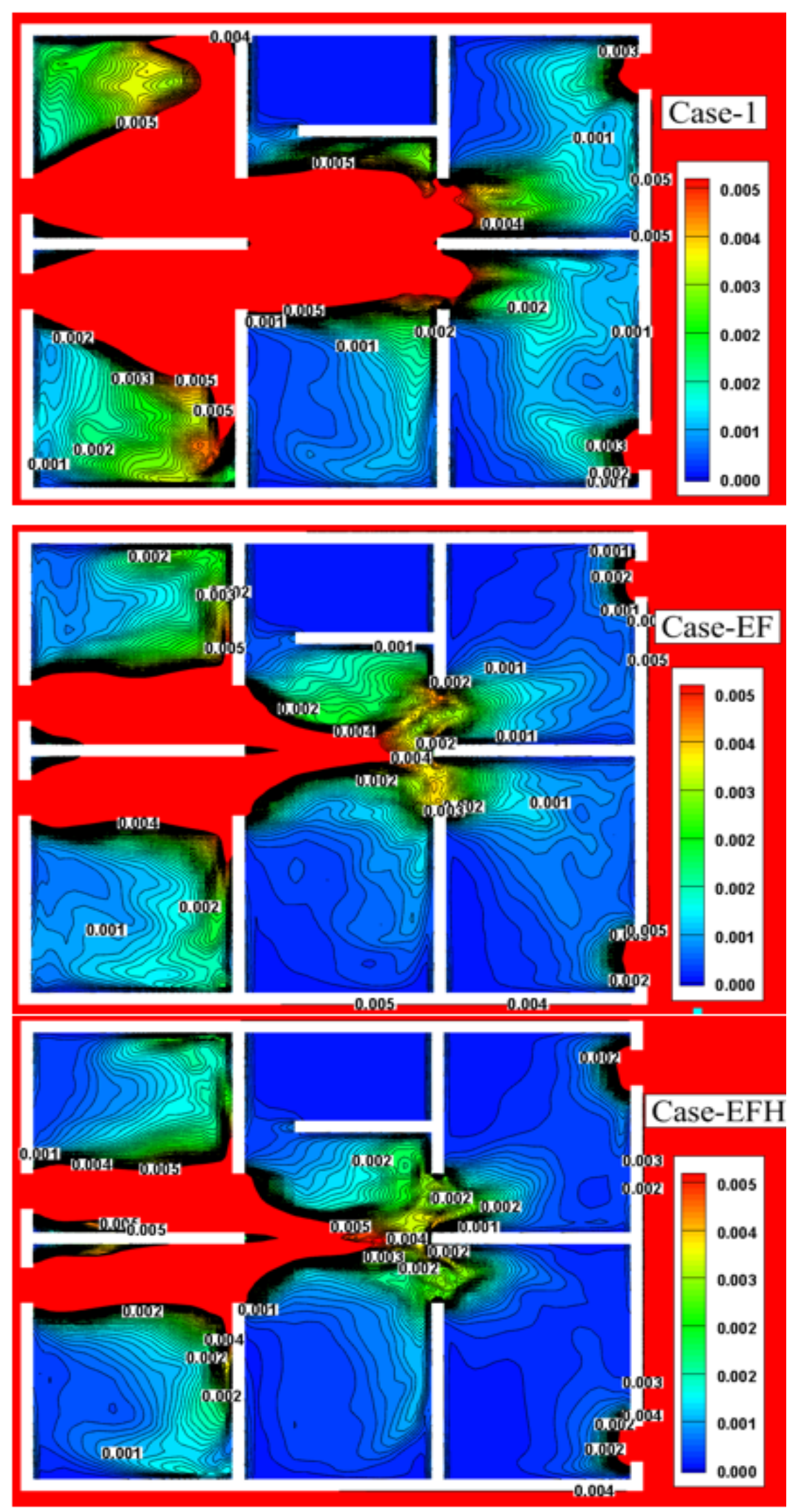

Fig. 17. Distribution of indoor turbulent kinetic energy $\left(\mathrm{k} / \mathrm{U}^{2} \mathrm{ref}\right)$ in the horizontal plane $(\mathrm{y} / \mathrm{H}=0.56)$. 


\section{Conclusion}

This study examined the impact of an external boundary wall on the indoor ventilation performance of the building using the CFD analysis. The computational model employed a widely used turbulence model in the ventilation section, the dynamic Smagorinsky LES model, and was validated against the available experimental data. The analysis on the three proposed cases included the average mean velocity, streamline distribution, and turbulent kinetic energy on the working plane of the CFD models exposed to the turbulent streams. The study found that the external wall, as an architectural element, helps to improve the distribution of indoor air flow by reducing the mean velocity and changing the airflow pattern within and around the building.

In summary, the following conclusions were reached:

- The study confirmed, in agreement with previous studies, that any change in environment factors can considerably affect the indoor air flow, in both the mean velocity magnitude and the distribution pattern, either positively or negatively.

- $\quad$ It was found that the boundary wall caused a reduction in the ventilation rate by around $48 \%$ in Case-EF and 67\% in Case-EFH compared with the basic case without the wall.

- Adding the boundary wall to the building can provide better distribution of the indoor mean velocity, and subsequently enhancing the indoor environment for occupants in terms of indoor airflow velocity.

- Increasing the height of boundary wall by around $20 \%$ did not produce noticeable improvement on the indoor mean velocity distribution.

- $\quad$ The flow patterns inside rooms A, B and C were all improved by adding the boundary wall in Case-EF and Case-EFH. 


\section{Acknowledgements}

The financial support from the Ministry of Higher Education and Scientific Research of Iraq is gratefully appreciated.

\section{References}

[1] G.C. da Graça, and P. Linden, Ten questions about natural ventilation of non-domestic buildings, Building and Environment 107 (2016) 263-273.

[2] A. A. Qasim, S. Gao, and A. K. Kareem, Energy saving and indoor thermal comfort evaluation using a novel local exhaust ventilation system for office rooms, Applied Thermal Engineering 110 (2017): 821-834.

[3] S. J. Emmerich, W. S. Dols and, J. W. Axley, Natural Ventilation Review and Plan for Design and Analysis Tools, National Institute of Standards Technology, (2011) NISTIR 6781.

[4] J. Feng, Z. Xu, and Y. Z, Natural ventilation potential analysis of office building in China. Journal of Tongji University, 36(1) (2008) 92-96.

[5] C. Chu, and B. Chiang, Wind-driven cross ventilation in long buildings, Building and Environment, 80 (2014) 150-158.

[6] S. Amos-Abanyie, C. Koranteng, and K.E. Apeatse, An evalution of the effects of external landscape elements on indoor airflow rate and paperns using Computational Fluid Dynamics, European Scientific Journal, 10 (14) (2014) 288-298.

[7] Y. Tamura, and Y. Ryuichiro, Advanced Environmental Wind Engineering. Springer, 2016.

[8] ASHRAE Standard 55-2013, Thermal environmental conditions for human occupancy, Atlanta: American Society of Heating, Refrigerating and Air-Conditioning Engineers Inc. (2013). [9] H. Montazeri, and R. Azizian, Experimental study on natural ventilation performance of onesided wind catcher, Building and Environment, 43 (2011) 2193-2202.

[10] H. Montazeri, Experimental and numerical study on natural ventilation performance of various multi-opening wind catchers. Building and Environment, 43 (2011) 370-378.

[11] H. Montazeri, F. Montazeri, R. Azizian, S. Mostafavi, Two-sided wind catcher performance evaluation using experimental, numerical and analytical modeling, Renew. Energy (35) 2010 1424-1435.

[12] M. H. Ghadiri, N. Lukman, N. Ibrahim, and M. F. Mohamed, Computational analysis of winddriven natural ventilation in a two sided rectangular wind catcher. Int. J. Vent. 12 (2013) 51-62.

[13] Y. C. Aydin, P. A. Mirzaei, Wind-driven ventilation improvement with plan typology alteration: A CFD case study of traditional Turkish architecture, Building Simulation, 10 ( 2017) 239-254.

[14] B. Blocken, T. Van Hooff, L. Aanen, and B. Bronsema, Computational analysis of the performance of a venturi-shaped roof for natural ventilation: Venturi-effect versus wind-blocking effect, Comput. Fluids 48 (2011) 202-213.

[15] T. Kobayashi, T. Chikamoto, and K. Osada, Evaluation of ventilation performance of monitor roof in residential area based on simplified estimation and CFD analysis, Building and Environments, 63 (2013) 20-30.

[16] C. M. Mak, J. L. Niu, C.T. Lee, and K.F Chen, A numerical simulation of wing walls using computational fluid dynamics, Energy and Buildings. 39 (2007) 995-1002. 
[17] P. Prajongsan, and S. Sharples, Enhancing natural ventilation, thermal comfort and energy savings in high-rise residential buildings in Bangkok through the use of ventilation shafts. Build. Environ. 10 (2012) 142-149.

[18] Z. T. Ai, C. M. Mak, J. L. Niu, Z. R. Li, and Q. Zhou, The effect of balconies on ventilation performance of low-rise buildings. Indoor Built. Environ. 2011, 20, 649-660.

[19] Z. T. Ai, C. M. Mak, J. L. Niu, and Z. R. Li, The assessment of the performance of balconies using computational fluid dynamics. Build. Serv. Eng. Res. Technol. 32 (2011) 229-243.

[20] H. Montazeri, and B. Blocken, CFD simulation of wind-induced pressure coefficients on buildings with and without balconies, Validation and sensitivity analysis. Building and Environments. 60 (2013) 137-149.

[21] M. F. Mohamed, S. King, M. Behnia, and D. Prasad, The effects of balconies on the natural ventilation performance of cross-ventilated high-rise buildings, Journal of Green Building 9.2 (2014) 145-160.

[22] J. Kindangen, Window and roof configurations for comfort ventilation. Build. Res. Inf. 25 (1997) 218-225.

[23] J. Kindangen, G. Krauss, and P. Depecker, Effects of roof shapes on wind-induced air motion inside buildings. Building and Environments, 32 (1997) 1-11.

[24] J.I. Perén, T. Van Hooff, B. C. C. Leite, and B. Blocken, Impact of eaves on crossventilation of a generic isolated leeward sawtooth roof building: Windward eaves, leeward eaves and eaves inclination, Building and Environments. 92 (2015) 578-590.

[25] J.I. Perén, T. Van Hooff, B. C. C. Leite, and B. Blocken, CFD simulation of wind-driven upward cross ventilation and its enhancement in long buildings: Impact of single-span versus double-span leeward sawtooth roof and opening ratio, Building and Environment 96 (2016) 142-156.

[26] B. G. Wiren, Effects of surrounding buildings on wind pressure distributions and ventilative heat losses for a single-family house." Journal of Wind Engineering and Industrial Aerodynamics, 15.1-3 (1983) 15-26.

[27] F. S. Bauman, D.R. Ernest, and E. A. Arens, The effects of surrounding buildings on wind pressure distributions and natural ventilation in long building rows, ASHRAE Transactions, 94 (2) (1988) 1670-1695.

[28] K. P., Lam, S. H., Kim, S. Satwiko, J. Jennings, and J. Cole, Assessment of the Effects of Environmental Factors on Air Flow in and Around Buildings. PLEA2006 - The 23rd Conference on Passive and Low Energy Architecture, Geneva, Switzerland, 2006.

[29] L. Tuan, A Abd Razak, S A Zaki, A F Mohammad , and M K Hassan, Large eddy simulation of natural ventilation for idealized terrace houses due to the effect of setback distance, IOP Conf. Series: Materials Science and Engineering 88 (2015) 012009.

[30] Z. Tong, C. Yujiao, and A. Malkawi, Defining the Influence Region in neighborhood-scale CFD simulations for natural ventilation design, Applied Energy 182 (2016) 625-633.

[31] A. Krishan, K. Jain, M. Rajgopalon, and P. Yewari, Shelter of form: the "process of design" in question, Proceedings of the Climatically Responsive Energy Efficient Architecture, PLEA 98 International Conference, A design Handbook. Vol.1: Basic Principles and Elements. Passive Low Energy Architecture International, New Delhi, 1995.

[32] A. Ikeguchi, G. Zhang, L. Okushima and J. C. Bennetsen. Windward windbreak effects on airflow in and around a scale model of a naturally ventilated pig barn. Transactions of the ASAE 46(3) (2003) 789-795.

[33] R. Aynsley, Natural Ventilation in Passive Design. BEDP Environment Design Guide (2007). 
The Royal Australian Institute of Architects.

[34] C. Gromke, R. Buccolieri, S. Di Sabatino, and B. Ruck, Dispersion study in a street canyon with tree planting by means of wind tunnel and numerical investigations - evaluation of CFD data with experimental data, Atmospheric Environment, 42(37) (2008) 8640-8650.

[35] R. Buccolieri, C. Gromke, S. Di Sabatino, and B. Ruck, Aerodynamic effects of trees on pollutant concentration in street canyons', The Science of the Total Environment, 407(19) (2009) 5247-5256.

[36] Z. Ai, and C. Mak, Analysis of fluctuating characteristics of wind-induced airflow through a single opening using LES modeling and the tracer gas technique, Building and Environment, 80(2014) 249-258.

[37] H. Cheng-Hu, M. Ohba, and R. Yoshiec. CFD modelling of cross ventilation using unsteady methods, The forth International Symposium on Computational Wind Engineering (CWE), 108 (2006) 255-258.

[38] M. Caciolo, P. Stabt, and D. Marchio, Numerical simulation of single-sided ventilation using RANS and LES and comparison with full-scale experiments, Building and Environment, 50 (2012) 202-213.

[39] J. Liu, and J Niu, CFD simulation of the wind environment around an isolated high-rise building: An evaluation of SRANS, LES and DES models, Building and Environment 96 (2016) 91-106.

[40] FLUENT User's Guide, November 2013.

[41] M. Germano, U. Piomelli, P. Moin, and W.H. Cabot, A dynamic subgrid-scale eddy viscosity model, Phys. Fluids A: Fluid Dynamics 3.7 (1991) 1760-1765.

[42] P. Gousseau, B. Blocken, T. Stathopoulos, and GJF van Heijst, CFD simulation of near-field pollutant dispersion on a high-resolution grid: A case study by LES and RANS for a building group in downtown Montreal. Atmospheric Environment, 45 (2011) 428-438.

[43] F. Porté-Agel, M. Pahlow, C. Meneveau, and MB Parlange, Atmospheric stability effect on subgrid-scale physics for large-eddy simulation. Advances in Water Resources, 24 (2001) 10851102.

[44] W-W. Kim, and S. Menon, Application of the localized dynamic subgrid-scale model to turbulent wall-bounded flows. Technical Report AIAA-97-0210 (1997). Proceedings of 35th Aerospace Sciences Meeting, Reno, USA.

[45] C.-H. Hu, M. Ohba, and R. Yoshie, CFD modelling of unsteady cross ventilation flows using LES, Journal of Wind Engineering and Industrial Aerodynamics 96 (10) (2008) 1692-1706.

[46] J. Franke, A. Hellsten, K.H. Schlunzen, and B. Carissimo, The COST 732 Best Practice Guideline for CFD simulation of flows in the urban environment: a summary, International Journal of Environment and Pollution, 44(1-4) (2011) 419-427.

[47] Y. Tominaga, A. Mochida, R. Yoshie, H. Kataoka, T. Nozu, M. Yoshikawa, and T. Shirasawa, AIJ guidelines for practical applications of CFD to pedestrian wind environment around buildings, Journal of wind engineering and industrial aerodynamics, 96(10) (2008) 1749-1761.

[48] I. B. Celik, Z. N. Cehreli and I. Yavuz, Index of Resolution Quality for Large Eddy Simulations, J. Fluids Eng 127(5) (2005) 949-958.

[49] S. B. Pope, Turbulent Flows, Cambridge University Press, Cambridge (2000).

[50] P. Richards, and R. Hoxey, Appropriate boundary conditions for computational wind engineering models using the $\mathrm{k}-\epsilon$ turbulence model, Journal of wind engineering and industrial aerodynamics, 46 (1993) 145-153.

[51] T. Van Hooff, B. Blocken, and T. Yoshihide, On the accuracy of CFD simulations of cross- 
ventilation flows for a generic isolated building: comparison of RANS, LES and experiments. Building and Environment, 114(2016) 148-165.

[52] P. Gousseau, B. Blocken, T. Stathopoulos, and GJF van Heijst, CFD simulation of near-field pollutant dispersion on a high-resolution grid: A case study by LES and RANS for a building group in downtown Montreal. Atmospheric Environment, 45 (2011) 428-438.

[53] P. Gousseau, B. Blocken, T. Stathopoulos, and G.J.F. van Heijst, Near-field pollutant dispersion in an actual urban area: analysis of the mass transport mechanism by high-resolution Large Eddy Simulations. Computers \& Fluids, 114 (2015) 151-162.

[54] Y. Jiang, M. Su, and Q. Chen, Using Large Eddy Simulation to Study Airflows in and around Buildings, ASHRAE Transactions, 109(2) (2003) 517-526.

[55] J. Hans, and JG Liu, Accurate, stable and efficient Navier-Stokes solvers based on explicit treatment of the pressure term, Journal of Computational Physics 199.1 (2004) 221-259.

[56] U.A. Hafiz, A. Hoda, and W. Asrar, A numerical investigation of explicit pressure-correction projection methods for incompressible flows, Engineering Applications of Computational Fluid Mechanics 9.1 (2015), 50-65.

[57] M. Ohba, K. Irie, and T. Kurabuchi, Study on air flow characteristics inside and outside a cross-ventilation model and ventilation flow rates using wind tunnel experimental, building, Journal of Wind Engineering and Industrial Aerodynamics, 89 (2001) 1513-1524.

[58] Y. Jiang, D. Alexander, H. Jenkins, R. Arthur, and Q. Chen, Natural ventilation in buildings: measurement in a wind tunnel and numerical simulation with large eddy simulation, Journal of Wind Engineering and Industrial Aerodynamics 91 (2003) 331-353.

[59] G. Evola, and V. Popov, Computational analysis of wind driven natural ventilation in buildings, Energy and buildings, 38(5) (2006) 491-501.

[60] M. P. Straw, Computation and measurement of wind induced ventilation, $\mathrm{PhD}$ thesis, University of Nottingham, 2000.

[61] W. Haojie, and Q. Chen, A new empirical model for predicting single-sided, wind-driven natural ventilation in buildings, Energy and Buildings 54 (2012) 386-394.

[62] Y. Jiang, and Q. Chen, Effect of fluctuating wind direction on cross natural ventilation in buildings from large eddy simulation, Building and Environment, 37(4) (2002) 379-386. 